\title{
Disruption of Arp2/3 Results in Asymmetric Structural Plasticity of Dendritic Spines and Progressive Synaptic and Behavioral Abnormalities
}

\author{
Il Hwan Kim, ${ }^{1}$ Bence Racz, ${ }^{5 *}$ Hong Wang, ${ }^{2,4 *}$ Lauren Burianek, ${ }^{1}$ Richard Weinberg, ${ }^{6}$ Ryohei Yasuda,, 4 \\ William C. Wetsel, ${ }^{1,2,3}$ and Scott H. Soderling ${ }^{1,2}$ \\ The Departments of ${ }^{1}$ Cell Biology, ${ }^{2}$ Neurobiology, and ${ }^{3}$ Psychiatry and Behavioral Sciences and Mouse Behavioral and Neuroendocrine Analysis Core \\ Facility, and ${ }^{4}$ Howard Hughes Medical Institute, Duke University Medical School, Durham, North Carolina, 27710, ${ }^{5}$ Department of Anatomy and Histology, \\ Faculty of Veterinary Science, Szent István University, 1078 Budapest, Hungary, and the ${ }^{6}$ Department of Cell Biology and Physiology, and Neuroscience \\ Center, University of North Carolina, Chapel Hill, North Carolina 27599
}

Despite evidence for a strong genetic contribution to several major psychiatric disorders, individual candidate genes account for only a small fraction of these disorders, leading to the suggestion that multigenetic pathways may be involved. Several known genetic risk factors for psychiatric disease are related to the regulation of actin polymerization, which plays a key role in synaptic plasticity. To gain insight into and test the possible pathogenetic role of this pathway, we designed a conditional knock-out of the Arp2/3 complex, a conserved final output for actin signaling pathways that orchestrates de novo actin polymerization. Here we report that postnatal loss of the Arp2/3 subunit ArpC3 in forebrain excitatory neurons leads to an asymmetric structural plasticity of dendritic spines, followed by a progressive loss of spine synapses. This progression of synaptic deficits corresponds with an evolution of distinct cognitive, psychomotor, and social disturbances as the mice age. Together, these results point to the dysfunction of actin signaling, specifically that which converges to regulate Arp2/3, as an important cellular pathway that may contribute to the etiology of complex psychiatric disorders.

\section{Introduction}

Dendritic spines are the primary targets of excitatory synaptic input. Their morphology is defined by an internal actin cytoskeleton, which forms a meshwork of filamentous actin (F-actin) (Korobova and Svitkina, 2010). Actin remodeling is crucial for the activity-dependent structural plasticity of spines and forms of long-term potentiation (LTP) and depression (LTD) (Kim and Lisman, 1999; Fukazawa et al., 2003; Zhou et al., 2004; Bosch and Hayashi, 2012). The Arp $2 / 3$ complex may be a major driver of spine actin remodeling, as it is specifically enriched within a sub-

\section{Received Jan. 4, 2013; revised Feb. 15, 2013; accepted Feb. 23, 2013.}

Author contributions: I.H.K., R.J.W., and S.S. designed research; I.H.K., B.L.R., H.W., and L.B. performed research; R.Y. and W.C.W. contributed unpublished reagents/analytic tools; I.H.K., B.L.R., H.W., R.J.W., and R.Y. analyzed data; I.H.K., R.J.W., W.C.W., and S.S. wrote the paper.

This work was supported by National Institutes of Health Grant R01-NS059957 (S.H.S.), March of Dimes Grant 6-FY10-289 (S.H.S.), and a Duke Fellowship in Postdoctoral Training Program in Fundamental and Translational Neuroscience (I.H.K.). B.L.R. is supported by the János Bólyai Research Fellowship from the Hungarian Academy of Sciences and by the Hungarian Scientific Research Fund (OTKA, Grant\#K83830). Contributions by R.Y. and H.W. were supported by HHMI, NINDS (R01NS068410), and NIDA (R01DA027807). Contributions by I.H.K. and W.C.W. were supported in part by NIMH (U19 MH082441). Some of the experiments were conducted with equipment/software purchased with a grant from the North Carolina Biotechnology Center. R.J.W. is supported by NINDS (R01NS035527). Thanks to Jindong Ding, Susan Grand, Dr. Ramona M. Rodriguiz, Dr. Meng Chen, Caroline Kim, Clifford Heindel, and Nathan Hedrick for advice and technical support. We also thank Dr. Marc Caron and Dr. Brigid Hogan for useful comments and editing.

${ }^{*}$ B.R. and H.W. contributed equally.

Correspondence should be addressed to Scott H. Soderling at the above address, E-mail: scott.soderling@dm.duke.edu.

R. Yasuda's present address: Max Planck Florida Institute, Jupiter, FL 33458.

DOI:10.1523/JNEUROSCI.0035-13.2013

Copyright $\odot 2013$ the authors $\quad 0270-6474 / 13 / 336081-12 \$ 15.00 / 0$ membrane region (20-100 $\mathrm{nm}$ from the membrane) surrounding the spine head (Rácz and Weinberg, 2008). This complex is composed of seven subunits, which initiates branched filament polymerization to create actin meshworks such as that of the spine (Mullins et al., 1997). Arp2/3 is activated by neuronal WASP and WAVE1 proteins, downstream of Rho-family GTPases such as Cdc42 and Rac, which are themselves stimulated during LTP (Fortin et al., 2010; Murakoshi et al., 2011).

Abnormalities in dendritic spines are associated with multiple neuropsychiatric disorders, including intellectual disability (ID), schizophrenia (SZ), and autism spectrum disorders (ASD) (Rudelli et al., 1985; Comery et al., 1997; Glantz and Lewis, 2000; Ramakers, 2002; Govek et al., 2004; Kolomeets et al., 2005; Barros et al., 2009; Hayashi-Takagi et al., 2010; Hutsler and Zhang, 2010; Ito et al., 2010; Carlson et al., 2011; Penzes et al., 2011; Durand et al., 2012). Accumulating evidence suggests a link between actin remodeling pathways and psychiatric disorders. For example, the SZ susceptibility genes DISC1 and DTNBP1 regulate actin dynamics in dendritic spines via Kalirin7-Rac signaling and Abi1WAVE, respectively (Hayashi-Takagi et al., 2010; Ito et al., 2010). Likewise, the ASD susceptibility genes SHANK2 and SHANK3 function as spine scaffolding proteins for actin-regulatory molecules, including the Rac and Arp $2 / 3$ regulators $\beta$ PIX and cortactin (Hering and Sheng, 2003; Park et al., 2003; Wendholt et al., 2006). Pathogenic mutations of SHANK3 are also associated with abnormal spine actin remodeling (Durand et al., 2012). Regulators of Rho-family GTPases, including ArhGEF6, WRP/srGAP3, and OPHN1 as well as Rho-family effectors such as $P A K 3$ and 
LIMK1 have been linked to ID and SZ (Frangiskakis et al., 1996; Allen et al., 1998; Endris et al., 2002; Addington and Rapoport, 2009; Piton et al., 2011; Wilson et al., 2011; Ramakers et al., 2012). Together, these studies lead to the hypothesis that dysregulated actin remodeling may be a basis for multiple neurodevelopmental and psychiatric disorders.

Here, we tested this hypothesis by conditional mutagenesis of the Arp $2 / 3$ complex, to clarify the relationship between the de novo actin polymerization pathway in excitatory neurons and phenotypes relevant to psychiatric disorders. We demonstrate that loss of the critical Arp2/3 subunit, ArpC3, from postnatal excitatory neurons disrupts the balance of structural plasticity in dendritic spines, and leads to a gradual loss of spines and progressive development of multiple abnormal behaviors, resembling the progressive trajectory of certain psychiatric disorders, including SZ. These findings suggest the Arp2/3 pathway is a convergent endpoint for spine plasticity and maintenance, whose disruption in mice can model neuropsychiatric disorders.

\section{Materials and Methods}

Animals. Conditional ArpC3 knock-out animals were produced by homologous recombination at the Duke BAC Recombineering Core and the Duke Transgenic Core Facility (Durham, NC). Briefly, a targeting construct was prepared by bacterial artificial chromosome recombineering, placing LoxP sites flanking exon 2 of ArpC3. Embryonic stem cells selected for neomyocin resistance were screened for homologous recombination by PCR across the long and short targeting arms, using primers within and outside of the targeting cassette. For behavioral testing, CaMKII $\alpha$-Cre positive (stock no. 005359; The Jackson Laboratory) male and female mice from heterozygous breeding pairs were transferred to the Duke University Medical School Mouse Behavioral and Neuroendocrine Analysis Core Facility. Behavioral testing was conducted with WT and $\mathrm{cKO}$ littermates.

For the morphological studies, ArpC3 conditional knock-out mice were crossed with the SlickV-YFP-ER ${ }^{T 2}$ mouse line (generously provided by Dr. Guoping Feng, MIT, Cambridge, MA) and the Rosa26-lox-stoplox-tdTomato reporter line (generously provided by Dr. Fan Wang, Duke University, Durham, NC). ArpC3 conditional knock-out mice were also crossed with the CamKll $\alpha$-Cre line for TEM studies. Littermate male and female mice from heterozygous pairings were used in all experiments. All mice were housed in the Duke University's Division of Laboratory Animal Resources facilities and all procedures were conducted with a protocol approved by the Duke University Institutional Animal Care and Use Committee in accordance with National Institutes of Health guidelines.

Fluorescence recovery after photobleaching. P6 ArpC $3^{f / f}$ pups deeply anesthetized with isoflurane were decapitated; the hippocampus was rapidly dissected into medium containing the following (in mM): HEPES 25, $\mathrm{NaHCO}_{3}$ 2, sucrose 248, glucose 10, $\mathrm{KCl} 4, \mathrm{MgCl}_{2} 5, \mathrm{CaCl}_{2} 1$. Then, 350 $\mu \mathrm{m}$ slices were cut with a tissue chopper (Ted Pella) and transferred to the surface of membrane inserts (Millipore) placed in culture media containing the following (in mM): L-glutamine $1, \mathrm{CaCl}_{2} 1, \mathrm{MgSO}_{4} 2$, D-glucose 12.9, $\mathrm{NaHCO}_{3}$ 5.2, HEPES 30, insulin 0.001, ascorbic acid $0.53,20 \%$ heat-inactivated horse serum, $80 \%$ HEPS-based MEM $8.4 \mathrm{~g} / \mathrm{L}$. The $\mathrm{pH}$ was adjusted to 7.35 with $1 \mathrm{~N} \mathrm{NaOH}$ and osmolarity was adjusted to $320 \mathrm{Osm}$. Slice-containing plates were maintained in a $37^{\circ} \mathrm{C}$ incubator with $5 \% \mathrm{CO}_{2}$. Five days after incubation, cultures were transfected biolistically with a gene gun. To make bullets, $40 \mu \mathrm{g}$ of GFP-actin and $30 \mu \mathrm{g}$ of Cre recombinase (pBeta-actin promoter) constructs were used with 12 $\mathrm{mg}$ of $1.6 \mu \mathrm{m}$ gold particles (Bio-Rad).

Five days after transfection, membrane inserts were transferred to 5 $\mathrm{cm}$ Petri dishes and filled with preincubated culture media. Baseline fluorescent intensities of randomly selected spines were measured three times, and then bleached with a $488 \mathrm{~nm}$ laser at $100 \%$ intensity for 5 iterations, using an upright LSM 780 with $20 \times$ water-immersion lens (Zeiss) at a pixel dwell time of $124 \mu \mathrm{s}$. Recovery of the fluorescence signal on individual spines was measured and collected every second, using Zen software (Zeiss). Background fluorescence was subtracted from that of target spine. Collected data (200 time points) were then normalized to the average intensity of the first 3 baseline trials. Control unbleached adjacent spines were monitored to ensure that bleaching was restricted to the spine under study. Time constants were calculated using SigmaPlot 10.0 software and curve fitting with a single exponential equation $[y=$ $\left.a^{*}\left(1-\exp \left(-b^{\star} x\right)\right)\right]$.

Analysis of dendritic spines in vivo. Triple mutants $\left(\operatorname{ArpC} 3^{f / f}: S l i c k V\right.$ $Y F P-E R^{T 2}$ :Rosa26-lox-stop-lox-tdTomato) were treated with tamoxifen ( $5 \mathrm{mg}$; daily oral administration) for $5 \mathrm{~d}$ from P30. One week, 2 weeks, 4 weeks, and 8 weeks after the last tamoxifen treatment, brain sections ( 40 $\mu \mathrm{m}$ ) were prepared and immunostained (see Immunohistochemical methods, below). Images of dendritic spines in secondary or tertiary branches of pyramidal neurons in CA1 region of hippocampus were taken on a LSM 710 confocal microscope (Zeiss). All images were acquired by $z$-series $(0.13 \mu \mathrm{m}$ intervals $)$ using a $63 \times$ oil-immersion objective. The $z$-series were deconvolved by Huygens Essential deconvolution software (SVI) and then 3-D reconstructed, measured, and classified by Imaris software (Bitplane). The criteria for classifying the spines were as follows: Stubby, length (spine) $<0.8 \mu \mathrm{m}$; Mushroom, length(spine) $<3$ $\mu \mathrm{m}$ and max_width (head) $>$ mean_width $(\text { neck })^{*} 2$; Long thin, mean_width (head) $>=$ mean_width (neck); Filopodia: true.

Glutamate uncaging. Glutamate uncaging was performed as described previously (Murakoshi et al., 2011). Slice preparation and biolistic transfection were performed as described for the FRAP experiments. A Ti: Sapphire laser was tuned to $720 \mathrm{~nm}$ to uncage the caged glutamate in artificial CSF (ACSF) that contained (mM): $\mathrm{NaCl} 130.0, \mathrm{KCl} 2.5$, $\mathrm{NaHCO}_{3} 2,0, \mathrm{NaH}_{2} \mathrm{PO}_{4} 1.25$, glucose 25.0, $\mathrm{CaCl}_{2}$ 4.0, tetrodotoxin 0.001, and MNI-caged L-glutamate 2.0 at $25-27^{\circ} \mathrm{C}$. Structural LTP was induced by $4-7 \mathrm{~ms}, 5-8 \mathrm{~mW}$ uncaging pulses applied at $0.5 \mathrm{~Hz}$ for 30 pulses. Spines of neurons expressing mCherry and EGFP were imaged with a $1030 \mathrm{~nm}$ ytterbium-doped laser. Volume change was monitored by measuring the change in the intensity of EGFP or mCherry fluorescence.

Golgi-Cox staining. Golgi-Cox staining procedures were performed as described previously (Deng et al., 2010). Mice were deeply anesthetized with isoflurane and then transcardially perfused with $4 \%$ PFA. Brains were removed and treated with solutions A and B from the FD Rapid GolgiStain Kit for 2 weeks, and then treated with solution $\mathrm{C}$ for $7 \mathrm{~d}$. Sections (100 $\mu \mathrm{m}$ thick) were cut by cryostat and transferred to solution $\mathrm{C}$ and incubated for $24 \mathrm{~h}$ at $4^{\circ} \mathrm{C}$. After brief rinsing with distilled water, floating sections were stained consecutively with solutions $\mathrm{D}$ and $\mathrm{E}$ for 30 min and then transferred to a $0.05 \%$ gelatin solution. Sections were mounted on glass slides, dehydrated through a graded series of ethanol concentrations, and then mounted with Permount. Images were collected by a MicroPublisher 5.0 MP color camera (QImaging) on a Zeiss Axio Imager microscope under a $100 \times$ oil-immersion objective using MetaMorph 7.6.5 software. For quantification, spine density from segments of secondary or tertiary branches of CA1 pyramidal neurons in the stratum radiatum of the hippocampus were measured.

Electron microscopy. Transmission electron microscopy was performed as described previously (Rácz and Weinberg, 2008). Mice were deeply anesthetized by isoflurane, then transcardially perfused with saline, followed by a mixture of depolymerized paraformaldehyde (4\%) and glutaraldehyde $(0.2-2 \%)$ in $0.1 \mathrm{M}$ phosphate buffer, $\mathrm{pH} 7.4 ; 50 \mu \mathrm{m}$ coronal sections were cut with a Vibratome. Sections for electron microscopy were postfixed in $1 \%$ osmium tetroxide in $0.1 \mathrm{~m}$ phosphate buffer for $40 \mathrm{~min}$ and stained en bloc with $1 \%$ uranyl acetate for $1 \mathrm{~h}$. After dehydration in an ascending ethanol series and propylene oxide, sections were infiltrated with Epon/Spurr's resin (EMS) and flat-mounted between sheets of ACLAR plastic (EMS) within glass slides. Sixty nanometer sections were cut with a Reichert Ultramicrotome (Leica), mounted on 300 mesh copper grids, they were contrasted with Ultrostain II lead (Fisher Scientific) and examined in a JEOL T1100 electron microscope at $80 \mathrm{KV}$; images were collected with a 12 bit $1024 \times 1024$ CCD camera.

Electron micrographs of randomly selected fields were taken from the middle of the stratum radiatum of CA1 hippocampus and layers 4-5 of the cerebral cortex for further analysis. Three-dimensional reconstructions were performed on the electron micrographs obtained from $50 \mathrm{~nm}$ serial sections mounted on Formvar-coated single slot nickel grids of $A r p C 3^{f / f}$ and cKO ArpC $3^{f / f}:$ CaMKII $\alpha$-Cre mice. On electron micro- 
graphs, apical dendrites of pyramidal neurons were identified and serial sections were aligned, and reconstructed in three dimensions using the freely available RECONSTRUCT software (SynapseWeb, Kristen M. Harris, PI, http://synapses.clm.utexas.edu/). Spine circularity was defined as $4 \pi$ (area/perimeter $\left.{ }^{2}\right)$, so a perfectly round profile would have a value of 1.0, and a line would have a value of 0 .

Chemical LTD. Slice preparation, biolistic transfection, and imaging were performed as described for the FRAP experiments. Following transfection with GFP (control) or with GFP with Cre (KO) for 5-7 d, baseline fluorescent intensities of spines were captured three times ( 2 min inter$\mathrm{val}$ ), and then the slices were treated with prewarmed culture media containing $20 \mu \mathrm{M}$ NMDA for $3 \mathrm{~min}$. After washing with normal culture media, the Petri dish containing the membrane insert was filled again with normal culture media and then spines were monitored every 2 min for 32 min using an upright LSM 780 with $20 \times$ water-immersion lens (Zeiss). The spine volume was measured by ImageJ software $(\mathrm{NIH})$ with an equation of (target area ${ }^{\star}$ target intensity) - (baseline area ${ }^{\star}$ baseline intensity). Collected data (18 time points) were then normalized to the average spine volume of the first three baseline trials.

Subcellular fractionation. Subcellular fractionation was performed as described previously (Kim et al., 2009). Briefly, mice were deeply anesthetized with isoflurane and hippocampi were rapidly removed, homogenized with 10 strokes using a Teflon-glass homogenizer in ice-cold lysis buffer containing the following (in mM): sucrose 320, HEPES 4, pH 7.4, EGTA 1, and protease/phosphatase inhibitors. The homogenate was centrifuged at $700 \times g$ for $10 \mathrm{~min}$ at $4^{\circ} \mathrm{C}$. The supernatant (S1) was centrifuged again at $12,000 \times g$ for $15 \mathrm{~min}$ to obtain the synaptosomal fraction (P2). For separating synaptosomal cytosol (LS1) and synaptosomal membrane (LP1), the pellet (P2) was hypo-osmotically lysed (5\% lysis buffer; $95 \%$ distilled water containing 5\% CHAPS and protease/phosphatase inhibitors) for $30 \mathrm{~min}$ and centrifuged at 35,000 $\times \mathrm{g}$ for $20 \mathrm{~min}$. The pellet (LP1) was resuspended in lysis buffer containing $1 \%$ Triton $\mathrm{X}-100$ and sonicated. The protein concentration was determined with the Bradford protein assay (Bio-Rad).

Western blotting. Ten micrograms of samples were electrophoresed through 12\% SDS-PAGE (Bio-Rad), transferred onto a nitrocellulose membrane (Whatman), and blocked with $5 \%$ nonfat dry milk in TRISbuffered saline (TBS; pH 7.4) containing 0.05\% Tween-20. For detection, the membranes were probed with primary antibodies for $24 \mathrm{~h}$ at $4^{\circ} \mathrm{C}$. The following primary antibodies were used: mouse anti-GluN2B monoclonal antibody (BD), mouse anti-GluN1 monoclonal antibody (Synaptic Systems), rabbit anti-GluA1 polyclonal antibody (Millipore), mouse anti-GluA2 monoclonal antibody (Zymed), rat anti-PSD95 monoclonal antibody (LifeSpan BioSciences), mouse anti-CamKll- $\alpha$ monoclonal antibody (Zymed), rabbit anti-p-CamK1l ${ }^{\mathrm{T} 286}$ polyclonal antibody (Millipore Bioscience Research Reagents), rabbit anti-p-Cam$\mathrm{K}^{\mathrm{T}}{ }^{\mathrm{T} 05 / 306}$ polyclonal antibody (Novus), rabbit anti- $\beta$-actin polyclonal antibody (Abcam), rabbit anti-ArpC2 polyclonal antibody (Millipore), and mouse anti-ArpC3 monoclonal antibody (BD). After washing, the membranes were incubated with horseradish peroxidase-conjugated secondary antibodies (GE Healthcare Life Sciences) for $1 \mathrm{~h}$, washed, and then developed using the ECL system (Thermo Scientific). Membranes were then exposed to autoradiography films (Genesee Scientific), and the films were scanned with an Epson 1670 at 600 dpi. The optical densities of bands were quantified with ImageJ software (NIH).

Immunohistochemistry. Immunohistochemistry was performed as described previously (Kim et al., 2009). Briefly, mice were deeply anesthetized with isoflurane and then perfused transcardially with TBS, pH 7.4, containing $25 \mathrm{U} / \mathrm{ml}$ heparin, followed by $4 \%$ paraformaldehyde (PFA) in TBS. Brains were removed, postfixed overnight at $4^{\circ} \mathrm{C}$ in the same fixative, and then cryo-protected with $30 \%$ sucrose in TBS. Brains were cut into $40 \mu \mathrm{m}$ sagittal sections by cryostat (Leica CM 3000), and stored at $-20^{\circ} \mathrm{C}$ until use. Sections were treated with blocking solution (TBS containing 5\% normal goat serum and $0.2 \%$ Triton X-100) for $2 \mathrm{~h}$ and incubated overnight at $4^{\circ} \mathrm{C}$ with chicken anti-GFP polyclonal antibody (Abcam) and rabbit anti-RFP polyclonal antibody (Rockland). After washing three times with TBS containing $0.2 \%$ Triton X-100, sections were incubated with IgG conjugated to Alexa Fluor 488 IgG or Alexa Fluor $555 \mathrm{IgG}$ (Invitrogen) for $1 \mathrm{~h}$ at room temperature. Sections were counterstained with a 4',6-diamidino-2-phenylindole solution (DAPI; Sigma-Aldrich). After washing four times, the sections were coverslipped with FluorSave (CalBioChem) aqueous mounting medium.

Primary neuronal culture and immunocytochemistry. Primary neuronal cultures from mouse hippocampus were prepared as described previously (Carlson et al., 2011). Briefly, P0 pups were rapidly decapitated and hippocampal neurons were collected, pooled, and plated onto poly- $l$ lysine-treated coverslips. Neurons were cultured in Neurobasal A medium supplemented with $2 \%(\mathrm{v} / \mathrm{v})$ B-27 supplement and $1 \%(\mathrm{v} / \mathrm{v})$ GlutaMAX (Invitrogen). Neuronal transfections were performed with $5.0 \mu \mathrm{g}$ of pCAG-Cre-GFP using Lipofectamine 2000 (Invitrogen) according to the manufacturer's instructions on DIV5 after plating. To detect endogenous ArpC3 by immunocytochemistry, samples were fixed at DIV8 in $4 \% \mathrm{PFA} / 4 \%$ sucrose in PBS for $15 \mathrm{~min}$ at $37^{\circ} \mathrm{C}$. They were permeabilized and blocked with $0.2 \%$ Triton X-100 and 5\% normal goat serum in TBS at room temperature for $20 \mathrm{~min}$. Samples were then incubated with a mouse anti-ArpC3 monoclonal antibody (BD) overnight at $4^{\circ} \mathrm{C}$. After washing with TBST (TBS containing $0.2 \%$ Triton X-100), samples were incubated with Alexa Fluor $555 \mathrm{IgG}$ for $1 \mathrm{~h}$ at room temperature. After washing four times, coverslips were mounted onto the glass slides using FluorSave (CalBioChem) aqueous mounting medium and imaged on a Zeiss LSM 710.

Open field test. Mice were placed into an open field (AccuScan Instruments) and their activities were monitored over $1 \mathrm{~h}$ under 350 lux illumination using VersaMax software (AccuScan Instruments). Locomotor activity (distance traveled), rearing (vertical beam-breaks), stereotypical activities (repetitive beam-breaks $<1 \mathrm{~s}$ ), and anxiety level (duration in center area of arena) were measured in 5 min time-bins.

Prepulse inhibition. Prepulse inhibition (PPI) of the acoustic startle response was measured with SDI equipment. After 5 min of acclimation to the apparatus, mice were given three different types of trials: trials with the startle stimulus only ( $40 \mathrm{~ms} 120 \mathrm{~dB}$ ); trials with the prepulse stimuli (20 ms) that were 4,8 , or $12 \mathrm{~dB}$ above the white-noise background (64 $\mathrm{dB}$ ) and followed $100 \mathrm{~ms}$ later with the startle stimulus; and trials with background stimuli (null trials) to control for background movements of the animals. Each test session began with 7 startle trials, followed by blocks of 5 null, 15 prepulse, and 9 startle trials presented in a pseudorandom order, and ending with 5 startle trials. The average intertrial interval was $15 \mathrm{~s}$, with a range of 12 to $30 \mathrm{~s}$. The peak startle response for each trial was measured between 35 and $65 \mathrm{~ms}$ after the onset of the startle stimulus. PPI was calculated as $\%$ PPI $=[1-$ (prepulse trials/startle-only trials) $]^{\star} 100$. The magnitude of the startle response was calculated as the mean response from all trials, excluding the initial block or 7 and final block of 5 trails.

Social affiliation test. The test apparatus consisted of three-chambers $(54 \times 26 \times 24 \mathrm{~cm})$ illuminated at 80-110 lux. This test was composed of two phases: nonsocial exploration and social affiliation testing. In the first phase, the $A r p C 3^{f / f}$ or cKO ArpC $3^{f / f}$ :CaMKII $\alpha$-Cre mouse was placed into the center chamber and two small empty wire-mesh cages were located in each of the adjoining chambers. The mice were given full access to all three chambers for $10 \mathrm{~min}$. The mouse was removed to its home cage and a $\mathrm{C} 3 \mathrm{H} / \mathrm{HeJ}$ mouse was placed into one of the wire-mesh cages while the other remained empty. For the second phase of testing, the $A r p C 3^{f / f}$ or cKO ArpC ${ }^{f / f}$ :CaMKII $\alpha$-Cre mouse were returned to the center chamber and given full access to the apparatus for $10 \mathrm{~min}$. All behaviors were videotaped across both test phases and analyzed by the TopScan program (CleverSys). Contact with a nonsocial or social stimulus was defined as the mouse approaching the wire-mesh cage and its nose being within $4 \mathrm{~cm}$ of the cage.

$Y$-maze. Spontaneous alternation in a Y-maze was conducted under indirect illumination (80-90 lux) in a 3-arm Y-maze. The mouse was placed into the center arm of the maze and permitted free exploration for $6 \mathrm{~min}$. All tests were recorded and scored subsequently by an observer who was blind to the genotypes of the mouse. Entry into an arm was defined as the mouse being $>1$ body length into that arm, with both hind-paws past the entrance to that arm. An arm alternation was defined as three successive entries into each of the different arms. Alternation, calculated as the total number of alternations divided by the total number of arm entries minus 2, was expressed as a percentage. 
Novel object recognition. This test was conducted using methods described previously (Carlson et al., 2011) with minor modifications under 80-100 lux illumination. Before testing, littermate mice were exposed for $10 \mathrm{~min}$ to the arena $(48 \times 22 \times 18 \mathrm{~cm})$ for three consecutive days without any objects. The test consisted of four phases (10 min each): training (day 1) and assessments of short-term memory (STM) (day1), long-term memory (LTM) (day 2), and remote memory (RM) (day 8). At training, two identical objects ( $\mathrm{T} 1$ and $\mathrm{T} 2$ ) were placed 10 $\mathrm{cm}$ away from opposite corners of the arena. A mouse was placed into center of the arena and given full access to the apparatus. After $20 \mathrm{~min}$, the mouse was returned to the arena and exposed to the now familiar (T1/2) and a novel object (N1) as a test for STM. Twenty-four hours later, the mouse was returned to the same arena with the familiar object (T1/2) and a second novel object (N2) as an assessment of LTM. Finally, RM was evaluated with the familiar object (T1/2) and a third novel object (N3). Behaviors were analyzed with Ethovision XT 7.0 software (Noldus Information Technology) and analyzed by an observer blinded to the genotype of the mice. Contact with a given object was defined as the mouse approaching the object nose first, with the nose being within $1 \mathrm{~cm}$ of the object. Duration of nose contacts with each object was measured. Preference scores were calculated as the [ (duration of contact with the novel object - duration of contact with the familiar object)/Total duration of contacts with both objects].

Statistical analyses. All data are expressed as means \pm SEM and all statistics were analyzed using SPSS programs (SPSS 20). Independent $t$-tests were used for analysis of differences between two groups. When comparing more than two groups, ANOVA and Tukey's post hoc tests were used. To monitor changes over time, repeated-measures ANOVA were run followed by Bonferroni corrected pairwise comparisons. A $p<0.05$ was considered statistically significant.

\section{Results}

Actin turnover defect in dendritic spines following ArpC3 deletion

To investigate a potential role for $\operatorname{Arp} 2 / 3$ in postnatal excitatory neurons in vivo, we generated an $\mathrm{ArpC} 3$ conditional allele targeting exon 2, circumventing the embryonic lethality associated with the germline deletion of $A r p C 3$ in mice (Yae et al., 2006). Studies confirmed the loss of ArpC3 within $72 \mathrm{~h}$ after Cre expression in $\operatorname{ArpC} 3^{f / f}$ mouse embryonic fibroblasts and hippocampal neurons (Fig. 1A,B).

ArpC3 protein was present in hippocampal synaptosomes, however, this was depleted in vivo upon Cre-mediated deletion of the floxed allele (Fig. 1C). Previous work has demonstrated that spine actin is predominantly filamentous and turns over rapidly (Star et al., 2002). To assess the impact of ArpC3 deletion on actin filament turnover within dendritic spines, a fluorescence recovery after photobleaching (FRAP) assay with ex vivo

E in each micrograph.
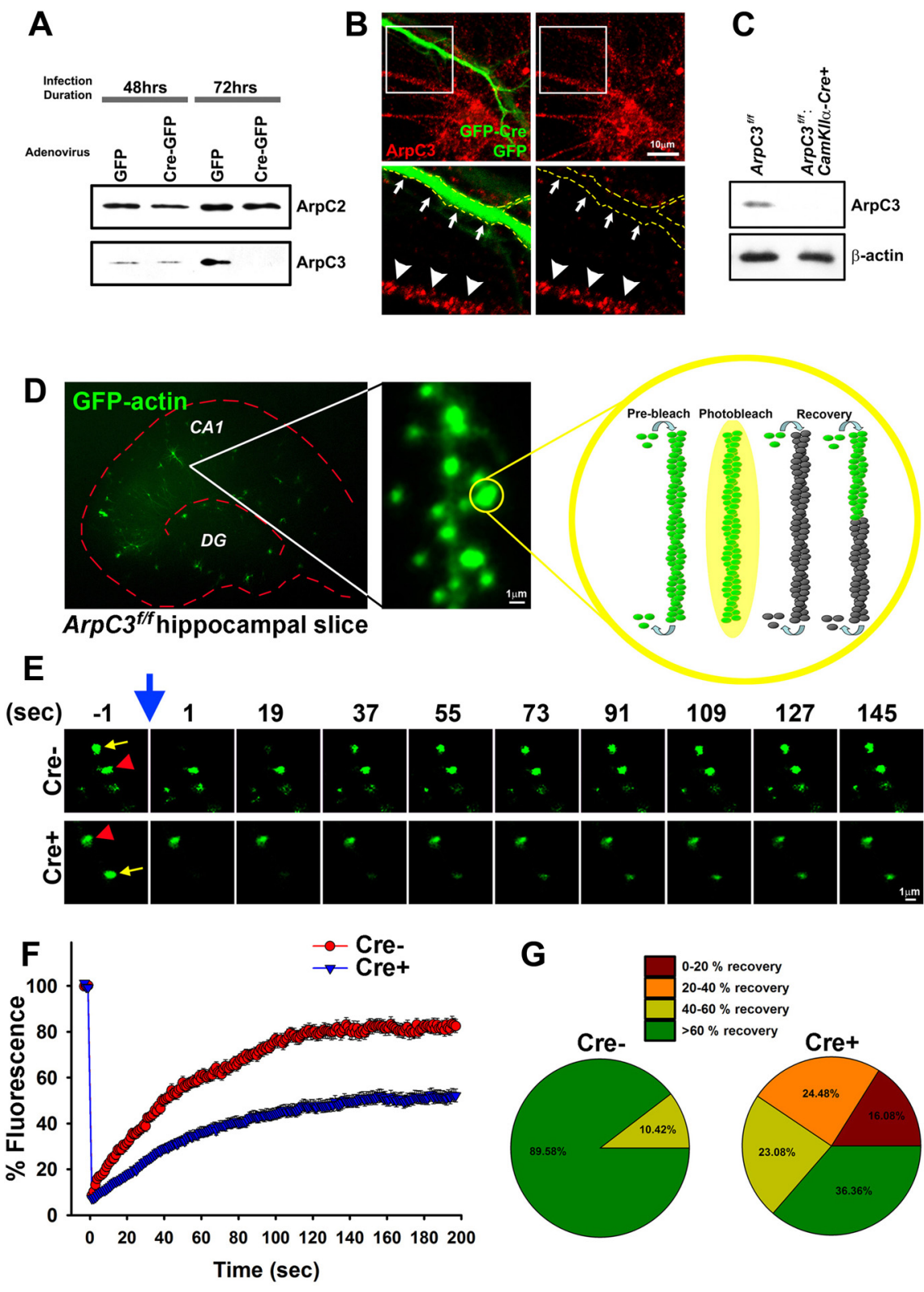

G
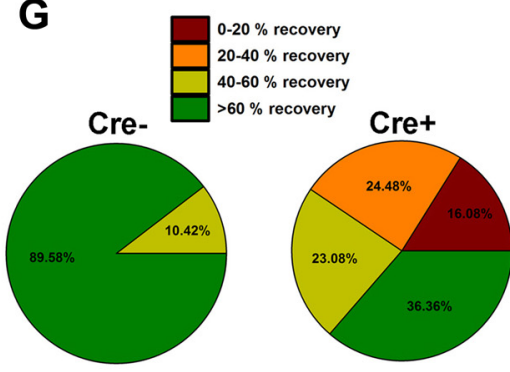

Figure 1. Reduced spine actin dynamics upon loss of ArpC3. A, Mouse embryonic fibroblasts (MEFs) were cultured from e13.5 $A r p\left(3^{f / f}\right.$ embryos and infected with either GFP or GFP-Cre adenovirus. Western blot analysis of lysates 48 and $72 \mathrm{~h}$ after infection confirmed the specific loss of ArpC3 at $72 \mathrm{~h}$ after infection (bottom), but not the related ArpC2 (top). B, Primary hippocampal neurons from $\operatorname{Arp}\left(3^{f / f}\right.$ mice were cultured and transfected with GFP-Cre or GFP (soluble fill). Seventy-two hours after transfection, neurons were immunostained for ArpC3 (red), which showed a punctate staining pattern within the cell body and neurites. GFP-Cre positive neuron (boxed region and outline) was negative for ArpC3 immunoreactivity. C, Synaptosomes purified from $\operatorname{ArpC} 3^{f / f}$ or ArpC $3^{\text {fff }}$ :CaMKIla-Cre mice were immunoblotted for ArpC3 (top) or $\beta$-actin as a loading control (bottom). D, Image of a hippocampal slice containing GFP-actin transfected neurons (left). GFP-actin is highly enriched in dendritic spines (middle). Schematic of photobleaching followed by recovery (right) illustrating that fluorescent recovery mainly depends on the turnover of existing actin filaments and reincorporation of freely-mobile unbleached GFP-actin monomers. $\boldsymbol{E}$, Representative image montages of Cre - (top) and Cre + (bottom panel) spines before and after (blue arrow) photobleaching (indicated by yellow arrows, unbleached spine is indicated by red arrowheads). $\boldsymbol{F}$, Graph depicting average fluorescence recovery for $\mathrm{Cre}-$ and $(\mathrm{re}+$ spines. $\boldsymbol{G}$, Average fraction of spines (last $30 \mathrm{~s}$ ) that recover, binned by extent of recovery, from 0 to $>60 \%$ recovery. Scale bars are indicated

$A r p C 3^{f f f}$ hippocampal slices was performed. Five days after expression of GFP-actin (control) or GFP-actin combined with Cre recombinase $(\mathrm{KO})$, we performed FRAP on randomly selected spines of CA1 pyramidal neurons (Fig. $1 D$ ).

After photobleaching, GFP-actin/Cre recombinase-expressing KO spines showed retarded and decreased actin filament turnover, 
A
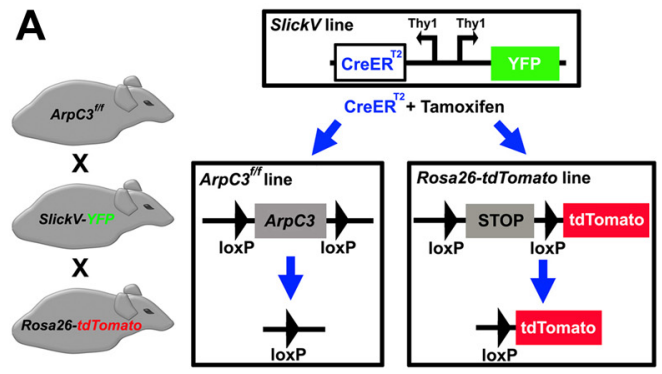

\section{B}
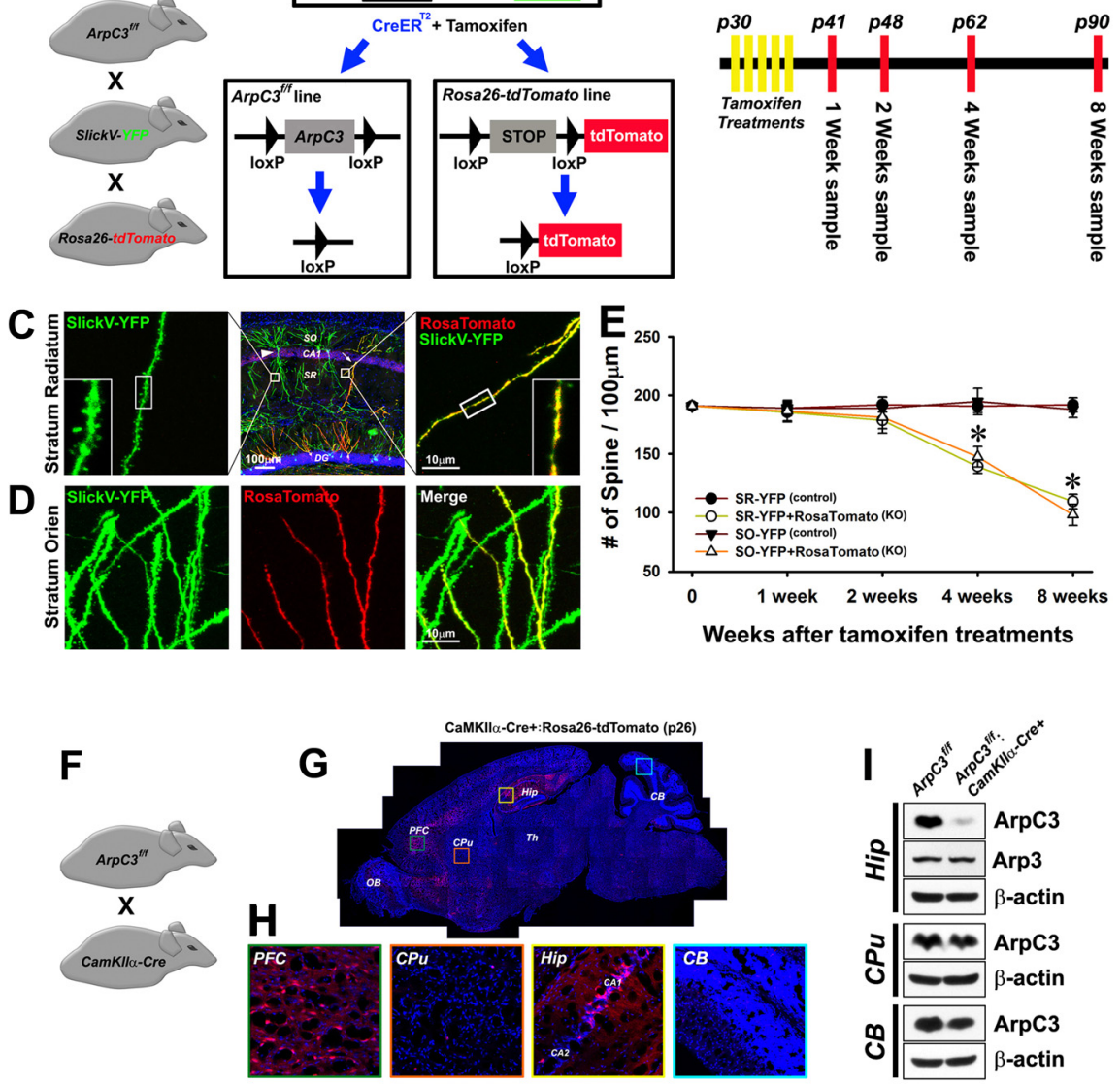

CaMKIIl $\alpha$-Cre+:Rosa26-tdTomato (p26)
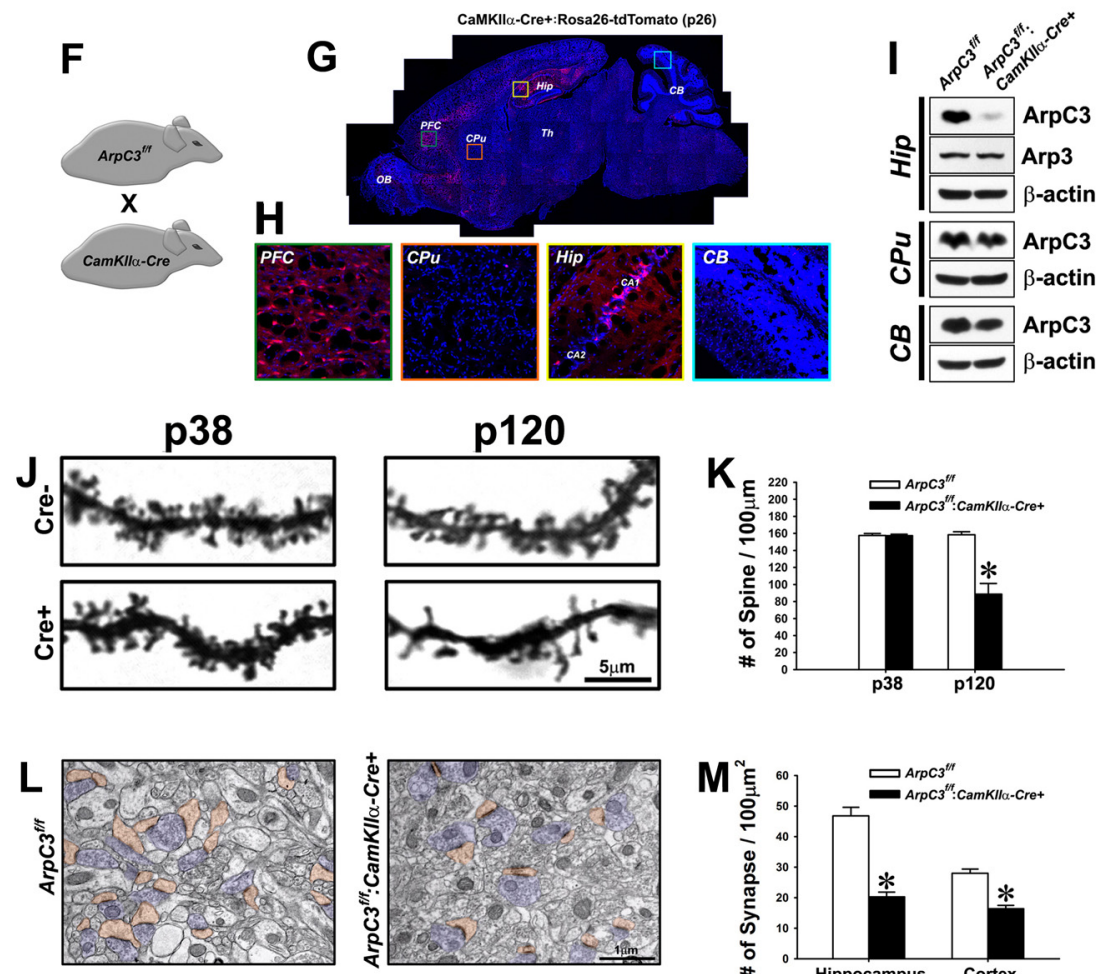

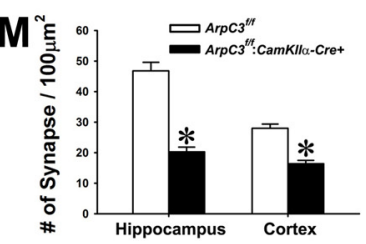

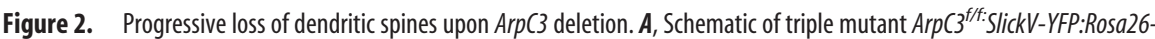
lox-stop-lox-tdTomato mice. Induction of Cre activity with tamoxifen treatment induces deletion of $\operatorname{Arp} C 3$ and a lox-stop-lox cassette to label neurons that have lost ArpC 3 with tdTomato. Neurons lacking Cre activity are only labeled with YFP. B, Timeline for experiments in the triple mutant mice showing the time-points for tamoxifen treatments and tissue collection. $C$, Representative confocal images showing YFP (control, left) and YFP + tdTomato (cK0, right) dendritic sections from the same tissue (middle; 8 weeks after tamoxifen). Regions of hippocampus are indicated; $S 0$, stratum oriens; $S R$, stratum radiatum; $D G$, dentate gyrus. $D$, Representative confocal images of dendritic sections from stratum oriens, showing YFP (left), tdTomato (Cre-positive; middle), and merge (right), indicating the selective loss of spines in (re-expressing neuron (8 weeks after tamoxifen). $\boldsymbol{E}$, Graph of spine density 1-8 weeks after tamoxifen treatment for control (YFP) and cKO (YFP +tdTomato) neurons from CA1 stratum radiatum (SR; $n=$ 11-15 neurons for each genotype and time-point) and stratum oriens ( $50 ; n=9-16$ neurons for each genotype and time-point) hippocampal regions. Two-way ANOVA for the numbers of spines revealed a significant main effect of time after Cre induction $\left(F_{(3,189)}=22.42, p<0.001\right)$ and group $\left(F_{(3,189)}=43.82, p<0.001\right)$, and a significant time $\times$ group interaction $\left(F_{(9,189)}=7.99\right.$, $p<0.001)$. Bonferroni-corrected pairwise comparisons noted that there were no significant differences in spine number among the four groups over the first 2 weeks after tamoxifen treatment. However, at 4 and 8 weeks the numbers of spines were significantly reduced in both SR and SO hippocampus in Cre + neurons compared with those in Cre - control neurons ( ${ }^{*} p<0.001$, from respective controls). $\boldsymbol{F}$, Arp $33^{f / f}$ :CaMKIIa-Cre mouse line. G, Representative sagittal section from CaMKIl $\alpha$-Cre:Rosa26-Iox-stop-lox-tdTomato compared with GFP-actin-expressing control spines (Fig. $1 E$ ), although no differences in basal levels of GFP-actin were noted in $\mathrm{KO}$ spines compared with WT spines. Control spines $(n=48)$ displayed $80 \%$ recovery of fluorescence within $100 \mathrm{~s}$ after photobleaching (average time constant 29.7 s), whereas GFP-actin/Cre recombinase-expressing spines $(n=143)$ showed a slowing of the recovery of fluorescence (average time constant 33.8 s) and a reduction of maximum fluorescence recovery $(<50 \%)$, indicating that actin remodeling is severely diminished by ArpC3 deletion (Fig. 1 F). Whereas $90 \%$ of WT spines recovered to at least $60 \%$ of the original fluorescence, only $36 \%$ of $\mathrm{KO}$ spines recovered to a similar extent; $16 \%$ of KO spines showed $<20 \%$ recovery (Fig. $1 G$ ), indicating a dramatic effect on spine actin dynamics consequent to the loss of ArpC3. These results demonstrate a critical role for the Arp2/3 complex in mediating normal actin dynamics in dendritic spines.

Gradual and profound loss of spine synapses by postnatal ArpC3 deletion We generated triple mutant $A r p C 3^{f / f}$ : SlickV-YFP-CreER ${ }^{T 2}$ :Rosa26-lox-stop-loxtdTomato-fluorescent protein mice to enable in vivo labeling and visualization of Cre-positive and -negative neurons after tamoxifen treatment (Fig. 2A). This approach allowed the morphology of neurons with and without Cre induction to be identified and compared within the same tissue. Moreover, Cre-mediated loss of

$\leftarrow$

mouse at P26. tdTomato expression (red), a marker of Cre activity, and DAPI nuclear stain (blue) are shown. $\boldsymbol{H}$, Boxed regions are expanded in $\mathbf{G}$ for the prefrontal cortex (PFC), caudate-putamen (CPu), hippocampal CA1 and CA2 (Hip), and cerebellum $(\mathrm{CB})$ regions. $\mathrm{OB}$, Olfactory bulb; Th, thalamus. I, Representative immunoblots from $\mathrm{Cre}+$ (Hip) and $\mathrm{Cre}-$ regions ( $\mathrm{CPu}, \mathrm{CB})$ for $\mathrm{ArpC} 3$, Arp3, and $\beta$-actin. Residual ArpC3 is likely to reflect Cre - hippocampal glia and interneurons. J, Visualization of spines from $\mathrm{ArpC}^{\mathrm{fff}}$ :CaMKIla-Cre mice compared with $A r p C 3^{f / f}$ controls by Golgi stain at P38 and P120. $K$, Graph of spine density at P38 and P120. Independent $t$ test showed no difference of spine density between $\mathrm{CKO}$ mice and littermate controls in P38 brains. However, P120 cK0 mice showed a significant decrease of spine density compared with their littermate controls $\left(t_{(1,4)}=6.71, p<0.01\right),{ }^{*} p<0.01$, from controls at P120. $L$, Representative electron micrographs showing postsynaptic spines (orange) and presynaptic butons (blue) in control and CK0 CA1 hippocampus at P120.M, Graph compares density of spine synapses in control and CKO sections from hippocampus [Cre $-(n=283$ axospinous synapses from 29 micrographs); (re + ( $n=196$ axospinous synapses from 46 micrographs), and cortex [ $\mathrm{Cre}-(n=181 \mathrm{axo}-$ spinous synapses from 31 micrographs); $(r e+(n=113$ axospinous synapses from 33 micrographs). ${ }^{*} p<0.001$, from respective controls. Scale bars in each micrograph are indicated. 
ArpC3 could be induced postnatally and any resulting changes in neuronal morphology could be followed over time (Fig. $2 B$ ).

Hippocampal sections (Fig. 2C,D) were prepared at 1-8 weeks after tamoxifen treatment (P30-P35) and the spine densities at each time point were measured. Surprisingly, there was no difference of spine density between $A r p C 3^{f / f}$ : Cre-positive (YFP/tdTomato doublepositive) KO neurons and $\operatorname{Arp} C 3^{f / f}$ :Crenegative (YFP single-positive) control neurons for the first 2 weeks after tamoxifen treatment (Fig. 2E). However, by 4 weeks, a gradual decline in the spine density of $\mathrm{KO}$ neurons was evident, with a $43 \%$ reduction of spines in the stratum radiatum at 8 weeks after tamoxifen (Fig. $2 E$ ). Thus, postnatal deletion of $A r p C 3$ induces a progressive loss of spines in vivo, rather than their immediate collapse.

To confirm this progressive loss of spines, we generated $\mathrm{ArpC} 3^{f / f}: \mathrm{CamKll} \alpha$-Cre mice (Fig. 2 F). CamKII $\alpha$-Cre expresses Cre recombinase extensively within pyramidal neurons of the CA1 hippocampal region and cortical sub-regions such as the prefrontal cortex by P20 (Tsien et al., 1996) (Fig. $2 G, H$ ). ArpC3 protein was specifically lost in regions expressing Cre (Fig. 2I). At P38 there were no differences between $A r p C 3^{f / f}$ and $A r p C 3^{f / f}: C a m K l l \alpha-C r e$ spine densities within the CA1 hippocampus by Golgi stain analysis (Fig. $2 J, K$ ). In contrast, at P120 there was a $44 \%$ decrease in spine density in the ArpC $3^{f / f}$ :CamKll $\alpha$ Cre samples (Fig. $2 J, K$ ), confirming the progressive spine loss observed in the triple mutant mice.

This postnatal spine loss is likely to reflect a corresponding loss of excitatory spine synapses, a phenomenon thought to contribute to several neuropsychiatric disorders (Feinberg, 1982; Glantz and Lewis, 2000). To verify this inference, spine synaptic contacts were further examined by transmission electron microscopy in the ArpC $3^{f / f}:$ CamKll $\alpha$-Cre mutant mice (Fig. $2 L$ ). At 4 months of age, ArpC $3^{f / f}$ :CamKll $\alpha$-Cre mice experienced a $56 \%$ loss of synapses onto spines in the stratum radiatum of the hippocampus, and a $41 \%$ loss of spine synapses within the cerebral cortex compared with controls (Fig. $2 M$ ), demonstrating that ArpC3 deletion results in extensive but delayed loss of synapses onto dendritic spines.

\section{Asymmetric structural plasticity in spines upon ArpC3 deletion}

The gradual loss of spines was unexpected, since Arp2/3 is believed to be responsible for the primary structure of actin within the spine (Korobova and Svitkina, 2010). We therefore asked whether more subtle, yet physiologically important effects occurred within the first 2 weeks of ArpC 3 deletion, when our FRAP analysis showed actin dynamics were affected, but before the onset of spine loss. Actin polymerization in spines is intimately
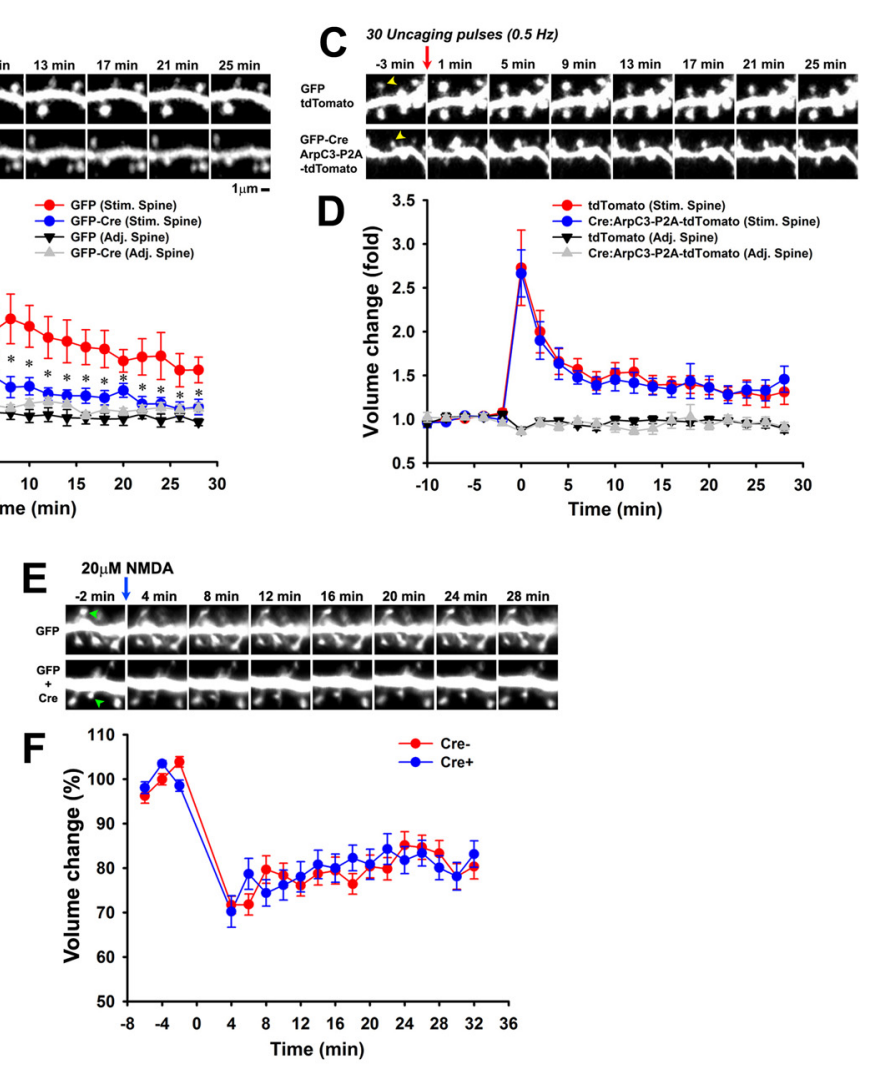

Figure 3. Asymmetric structural plasticity of spines by ArpC3 deletion. $A$, Representative time course images before and after glutamate uncaging showing control (top) and Cre-positive (bottom) spines. Time of uncaging is indicated above. Yellow arrowhead indicates stimulated spine. $\boldsymbol{B}$, Graph depicting averaged time course of spine volume change in the same experiments as in $\boldsymbol{A}$.

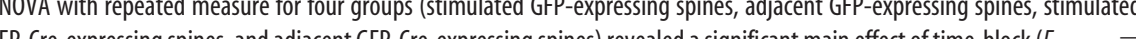
spines. Green arrowheads indicate spines showing marked volume loss. $\boldsymbol{F}$, Graph depicting averaged time course of spine volume change in the same experiments as in $\boldsymbol{E}$. No differences between $\mathrm{Cre}-$ control and Cre + spines are seen.

associated with LTP (Kim and Lisman, 1999; Fukazawa et al., 2003) and is required for spine structural plasticity associated with LTP (Okamoto et al., 2004). Rac, an upstream activator of Arp $2 / 3$ present in spines, is rapidly turned on following LTP induction (Fortin et al., 2010). We therefore determined whether Arp2/3 is required for structural plasticity by uncaging glutamate at single spines. $\operatorname{Arp} C 3^{f / f}$ hippocampal slices were biolistically transfected with GFP (control) or GFP-Cre (knock-out), together with mCherry as a soluble fill (Fig. $3 A$ ). Six to eleven days later, pulsed glutamate uncaging induced both transient and sustained phases of structural plasticity in GFP-control stimulated spines compared with adjacent unstimulated spines (Fig. 3B). In contrast, GFP-Cre knock-out neurons completely lacked the sustained phase of structural plasticity. This effect was rescued by the expression of recombinant ArpC3 (Fig. 3C,D), demonstrating that loss of ArpC3 prevents the maintenance of activity-induced enlarged spines, before the onset of spine loss.

Regulation of actin filaments in response to activity is bidirectional such that induction of LTD triggers spine shrinkage that is dependent on actin depolymerization (Zhou et al., 2004; Bosch 
A
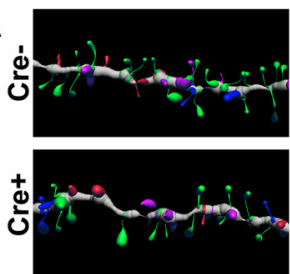

B

1 Week

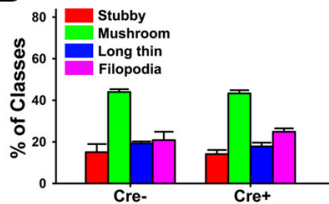

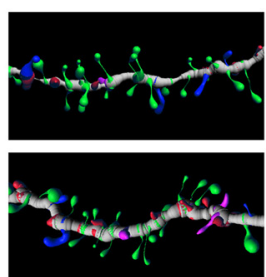

2 Weeks

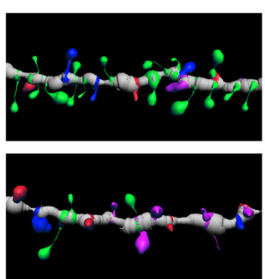

4 Weeks

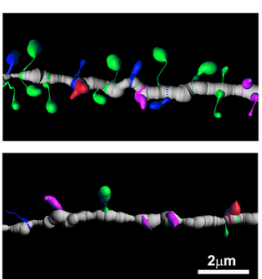

8 Weeks
C

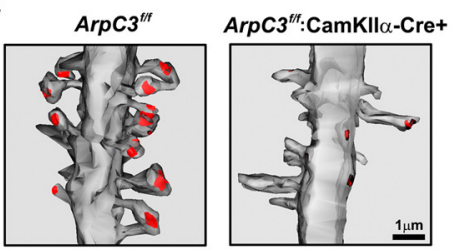

D

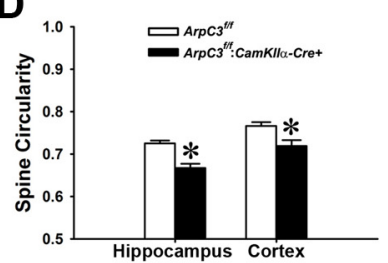

Figure 4. Altered spine morphology in $\operatorname{ArpC} 3$ CKO neurons. $A$, Reconstructed images from control ( $\mathrm{Cre}-$ ) and $\mathrm{CKO}$ (Cre + ) dendrites 1- 8 weeks after tamoxifen treatment from Arp C $3^{\text {fff }}$ :SlickV-YFP:Rosa26-lox-stop-lox-tdTomato neurons. Morphology of individual spines is color-coded according to the key in $\boldsymbol{B}$. $\boldsymbol{B}$, Graph depicting the percentage of each morphological class of spine over time after tamoxifen-mediated (re induction. ANOVA with repeated measure revealed significant main effects of spine-type $\left(F_{(3,288)}=178.7, p<0.001\right)$, spine-type $\times$ genotype $\left(F_{(3,288)}=21.375, p<0.001\right)$, spine-type $\times$ time $\left(F_{(9,288)}=10.76, p<\right.$ $0.001)$, and spine-type $\times$ genotype $\times$ time $\left(F_{(9,288)}=8.18, p<0.001\right)$. However, an interaction between genotype $\times$ time was not detected. Bonferroni-corrected pairwise comparisons noted that there were no significant differences in spine classes between genotypes over the first 2 weeks after tamoxifen treatment. However, at 4 weeks, mushroom-shaped spines in YFP + tdTomato double positive $\mathrm{KO}$ neurons were selectively decreased, whereas, filopodia-like spines were significantly increased compared with YFP single positive control neurons $\left({ }^{*} p<0.001\right)$. At 8 weeks after tamoxifen treatment, stubby and mushroom spines in YFP + tdTomato double positive $K O$ neurons were significantly decreased, whereas, filopodia-like spines were significantly increased compared with YFP single positive control neurons $\left({ }^{*} p<0.001\right) . n=13-15$ neurons per genotype were used for each time-point. C, Three-dimensional EM reconstructions of hippocampal dendrites from $\operatorname{Arp} C 3^{f / f}$ (control, left) and $A r p C 3^{f / f}: C a M K I / \alpha-$ $\mathrm{Cre}$ (CKO, right) mice showing representative differences in overall spine morphology and density. Postsynaptic density (PSD) is indicated in red. $\boldsymbol{D}$, Graph depicting the spine head circularity computed from electron micrographs from control $\operatorname{Arp}\left(3^{f / f}\right.$ and $c K 0$ $\operatorname{ArpC}^{f / f}$ :CaMKII $\alpha$-Cre mice; 1.0 corresponds to a perfect circle. Hippocampus ( $n=283$ for $\operatorname{ArpC} 3^{f / f}$ control, $n=196$ for $\operatorname{ArpC} 3^{f / f}$ : CaMKIl $\alpha$-Cre, ${ }^{*} p<0.001$, from control). Cerebral cortex ( $n=181$ for $\operatorname{ArpC} 3^{f / f}$ control, $n=113$ for $\operatorname{ArpC} 3^{f / f}$ :CaMKIIl $\alpha$-Cre, ${ }^{*} p<$ 0.01 , from control. Scale bars in each micrograph are indicated. dritic sections at multiple times following Cre induction using ArpC $3^{f f f}$ :SlickV-YFPCreER ${ }^{T 2}:$ Rosa26-lox-stop-lox-tdTomatofluorescent protein mice (Fig. 4A). At 1-2 weeks after Cre induction (when spine loss was not observed), there were no significant differences in morphology between control and cKO spines (Fig. 4B). In contrast, at 4 weeks after Cre induction, the fraction of mushroom type spines decreased ( $67 \%$ of Cre - control), while filopodia-like spines increased $(274 \%$ of $\mathrm{Cre}-$ control) in dendrites from $\mathrm{cKO}$ versus control. These alterations of spine morphologies were further exacerbated at 8 weeks after Cre induction. The fractions of mushroom and filopodia-like spines reached to $59 \%$ and $276 \%$ of their controls respectively, in addition to a decrease of stubby type spines ( $51 \%$ of $\mathrm{Cre}-$ control) at this time point (Fig. $4 B$ ), suggesting a delayed and gradual effect of ArpC3 deletion on spine morphology. These progressive changes in spine morphology were well matched with the progression of spine loss shown in Figure 2E. Morphological differences between control and knock-out spines were confirmed in EM sections from adult $\mathrm{ArpC} 3^{f / f}:$ CamKll $\alpha$ Cre mice (Fig. 4C). EM analysis also revealed that spine heads in $A r p C 3^{f / f}$ : CamKll $\alpha$-Cre mice were more elongated than those in $A r p C 3^{f / f}$ control mice (Fig. $4 D)$. Together, these data show that Arp $2 / 3$ is required for activity-dependent spine enlargement, and suggest this is important for maintaining an equilibrium of normal spine morphology that may be critical for the long-term maintenance of normal spine density. and Hayashi, 2012). We next addressed whether activitydependent spine shrinkage was intact in ArpC3 KO neurons. $\operatorname{ArpC} 3^{f / f}$ hippocampal slices were transfected with GFP (control) or GFP combined with Cre (knock-out) (Fig. $3 E$ ) to visualize spines. Five to seven days later, slices were treated with $20 \mu \mathrm{M}$ NMDA for 3 min to induce a chemical LTD (Lee et al., 1998). Monitoring spine volume revealed that both control and Crepositive KO spines were rapidly reduced to $70 \%$ of original volume, and maintained the reduced volume for over $30 \mathrm{~min}$ (Fig. $3 F$ ), indicating normal activity-dependent spine shrinkage in ArpC3-deficient neurons. Together, these data suggest the loss of ArpC3 uncouples the bidirectional modulation of spine morphology with plasticity. Thus, KO spines are likely to be biased toward LTD-induced spine shrinkage due to an asymmetry of activity-dependent morphological dynamics in $\mathrm{KO}$ spines.

Asymmetric spine structural plasticity is followed by an accumulation of filopodia-like spines

The asymmetric structural plasticity of $A r p C 3$ cKO neurons suggested that a progressive accumulation of morphologically immature spines may occur in vivo. To address this question, we classified spines based on 3D-reconstructed images of den-
Reduced glutamate receptor expression and CaMKII activation in synapses of $\mathrm{ArpC}^{\mathrm{f} / \mathrm{f}}$ :CaMKII $\alpha$-Cre mice Spine morphology is correlated with synapse strength; large mushroom-shaped spines contain larger postsynaptic densities and more glutamate receptors than thin or filopodial spines (Bourne and Harris, 2008). Since the actin cytoskeleton plays a critical role in regulating PSD-95 dynamics within the spine (Blanpied et al., 2008) and maintaining glutamate receptors within synapses (Zhou et al., 2001), we hypothesized that Arp2/3 may influence PSD composition. We therefore analyzed the contents of several PSD proteins in excitatory synapses of $A r p C 3^{f / f}$ : CamKll $\alpha$-Cre mice, using subcellular fractionation of hippocampi from 4-month-old brains (Fig. 5A). Western blot analysis of equal amounts of protein revealed significant reductions of GluN2B ( $-29 \pm 5 \%)$, GluN1 ( $-39 \pm 8 \%)$, GluA1 ( $-56 \pm 8 \%)$, GluA2 $(-26 \pm 10 \%)$, and PSD-95 $(-33 \pm 8 \%)$ in the PSDcontaining LP1 fraction of mutant hippocampi compared with controls (Fig. 5B), although the cytosolic (S2) level of GluA1 was not changed. Loss of these PSD proteins correlated well with the evidence of morphologically weaker spines. Functional weakening was further supported by estimating the level of activation of CaMKII, an enzyme downstream of NMDA receptor-mediated 

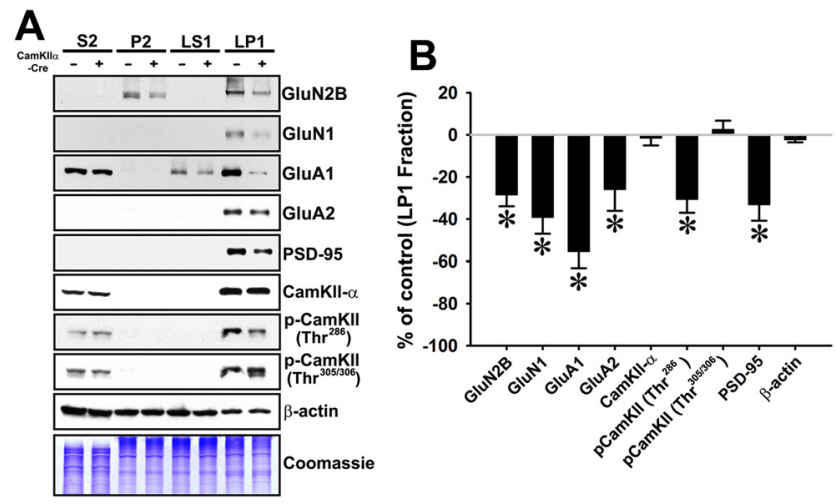

Figure 5. Reduced glutamate receptors and CamKIl activation in PSD of ArpC $3^{f / f}$ :CaMKII $\alpha$ Cre mice. $A$, Representative immunoblots of subcellular fractions from $\operatorname{ArpC}^{f f f f}(\mathrm{Cre}-; n=6)$ and $\operatorname{Arp} C{ }^{f / f}$ :CaMKII $\alpha$ - $C r e(C r e+; n=6)$ adult mice at P120. Antibodies used in each panel are indicated on the right. Bottom panel is a representative Coomassie-stained gel showing equivalent total protein loading for each fraction. S2, Cytosol; P2, crude synaptosome; LS1, synaptosomal cytosol; LP1, synaptosomal membrane. $\boldsymbol{B}$, Graph of levels of each PSD component in LP1 fraction as a percentage of control, quantified from immunoblots in $A$. Independent $t$ test revealed significant reductions of GluN2B $\left(t_{(1,10)}=5.82, p<0.001\right)$, GluN1 $\left(t_{(1,10)}=5.57\right.$, $p<0.001)$, GluA1 $\left(t_{(1,10)}=7.83, p<0.001\right)$, GluA2 $\left(t_{(1,10)}=2.85, p<0.05\right)$, p-CamKII ${ }^{\text {T286 }}$ $\left(t_{(1,10)}=5.32, p<0.001\right)$, PSD-95 $\left(t_{(1,10)}=4.84, p<0.001\right)$ in adult (P120) ArpC $3^{f / f}:$ CaMKIla-Cre mice compared with those of littermate controls. However, total CamKIl $\alpha, \mathrm{p}$-Cam$\mathrm{KII}^{\mathrm{T} 305 / 306}$, and $\beta$-actin levels did not show any significant difference between $\mathrm{CKO}$ mice and controls.

calcium influx (Strack and Colbran, 1998). Phosphorylation of CaMKIIThr ${ }^{286}$, indicative of CaMKII activation, was markedly decreased in the LP1 fraction of ArpC $3^{f / f}$ :CamKll $\alpha$-Cre mice $(-31 \pm 6 \%)$ (Fig. 5A,B). In contrast, no differences were observed between genotypes in total CaMKII levels or in phosphorylation of $\mathrm{Thr}^{305 / 306}$, a site correlated with CaMKII inactivation. Together, these data demonstrate that loss of ArpC3 leads to the accumulation of filopodial spines containing less PSD-95, fewer glutamate receptors, and reduced downstream activation of CaMKII.

\section{Progressive onset of abnormal behaviors in $\operatorname{ArpC} 3^{f / f}$ : CamKllo-Cre mice}

We noticed that the adult $A r p C 3^{f / f}:$ CamKll $\alpha$-Cre mice seemed hyperactive in the home cage and interacted less often with cagemates than their control littermates. These observations led us to conduct more detailed behavioral analyses of the mice. The experiments reported above suggested two phases of progressive cellular deficits - an early asymmetric structural plasticity of spines, followed by a later phase of extensive synapse loss. Accordingly, we assessed the potential sequence of behavioral alterations in young adolescents (P30-P40) and adults (P90-P120), to determine whether the progressive cellular defects were associated with a progressive onset of behavioral abnormalities.

Adolescent $A r p C 3^{f / f}$ :CamKll $\alpha$-Cre mice displayed levels of locomotor (Fig. 6A), repetitive activities (Fig. $6 C$ ), and rearing behaviors (Fig. $6 E$ ) similar to their control littermates. In contrast, adult (P90-P120) mutant mice showed a dramatic increase in locomotor activity (Fig. $6 \mathrm{~B}$ ), as well as increased repetitive behaviors (Fig. 6D) and rearing (Fig. 6F), demonstrating that their abnormal hyperactivity and stereotypical behavior had a delayed onset following the loss of ArpC3. However, both adolescent and adult $A r p C 3^{f / f}:$ CamKll $\alpha$-Cre mice spent similar time in the central area of the arena compared with their littermate controls (Fig. $6 G, H)$, suggesting normal anxiety levels in the mutant mice.

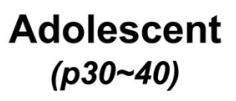

Adult

(p90 120)
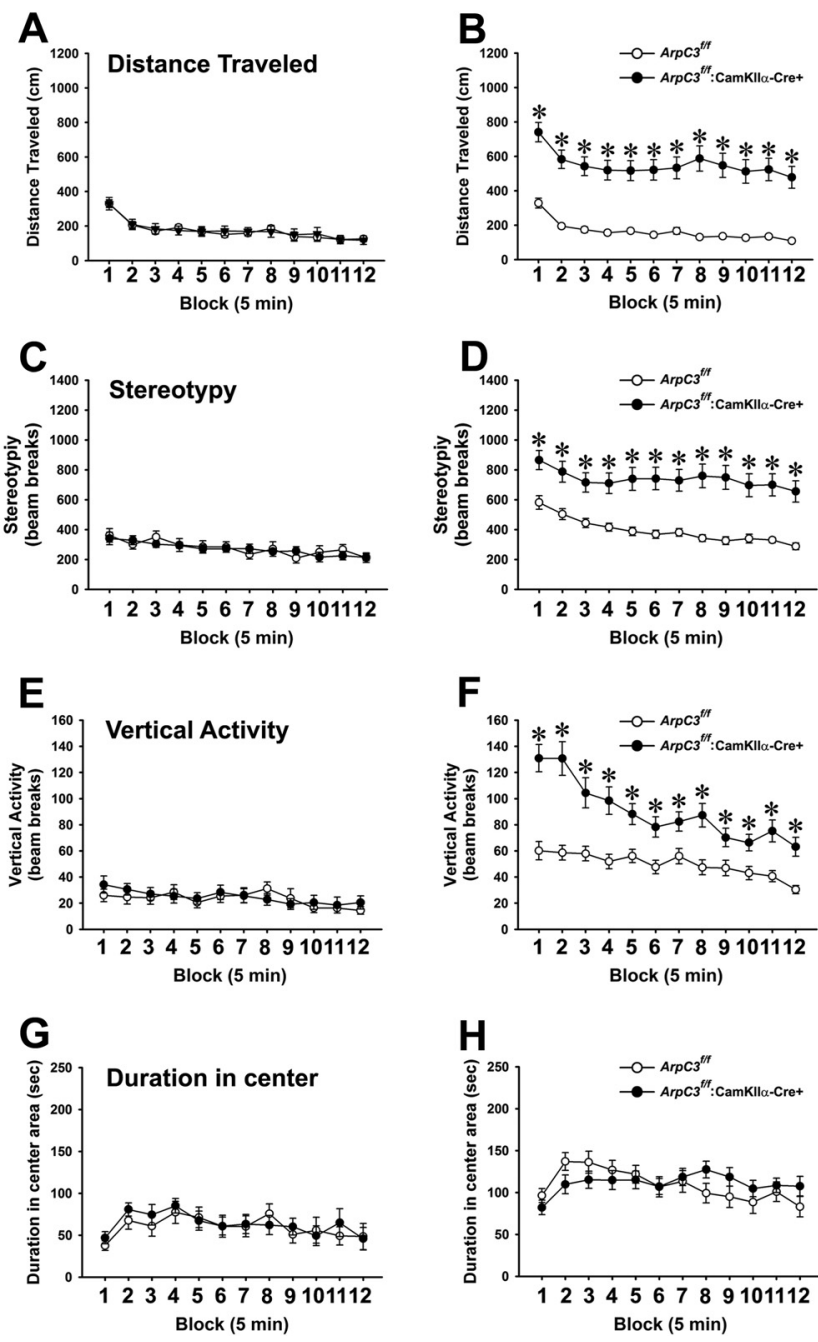

Figure 6. Analyses of open field behaviors in young and adult $\mathrm{Arp}\left(3^{\mathrm{fff} f}\right.$ :CaMKIll $\alpha$-Cre mice Analysis of behaviors of control $\operatorname{Arp} C 3^{f / f}$ and $\operatorname{ArpC} 3^{\mathrm{f} / f}$ :CaMKIl $\alpha$-Cre mice at P30-P40 $(\boldsymbol{A}, \boldsymbol{C}, \boldsymbol{E}, \boldsymbol{G})$ and at P90-P120 (B, D, $\boldsymbol{F}, \boldsymbol{H}) . \boldsymbol{A}, \boldsymbol{B}$, Distance traveled in the open field test (OFT) over $1 \mathrm{~h}$ in control and $\operatorname{ArpC} 3 \mathrm{cKO}$ mice (adolescent $n=15$ control, $n=13 \mathrm{cKO}$; adult $n=37$ control, $n=$ 43 (KO). Hyperactivity was increased only in adult cKO mice. ANOVA with repeated measure for activity levels of four groups (genotypes of both adolescent and adult) revealed significant main effects of time-block $\left(F_{(11,1144)}=19.70, p<0.001\right)$ and group $\left(F_{(3,104)}=21.57, p<0.001\right)$, but no time-block $\times$ group interaction. Bonferroni corrected pairwise comparisons revealed that activity levels of $c K 0$ mice were significantly higher than that of adolescent mice (both controls and $c K 0 s$ ) and adult littermate controls throughout all time points $\left({ }^{*} p<0.001\right) . C, D$, Stereotypical behavior as quantified by the number of repeated beam-breaks $<1 \mathrm{~s}$ in the open field. ANOVA with repeated measure for four groups revealed significant main effect of group $\left(F_{(3,104)}=16.44, p<0.001\right)$, but no time-block $\times$ group interaction. Bonferroni-corrected pairwise comparisons revealed no differences between adolescent control $\left(\operatorname{Arp} 3^{f / f}\right)$ and cKO $\left(\operatorname{ArpC} 3^{f f f}\right.$ :CaMKIlaCre) mice (C). However, the level of stereotypic behaviors of cKO mice were significantly higher than that of adolescent mice (both controls and $C K O s$ ) and adult littermate controls throughout all time points (D) $\left({ }^{*} p<0.001\right) . \boldsymbol{E}, \boldsymbol{F}$, Rearing behaviors in the open field as determined by the numbers of vertical beam-breaks for adolescent mice (left) and adult (right) mice. ANOVA with repeated measure of four groups revealed significant main effect of group $\left(F_{(3,104)}=21.23, p<0.001\right)$, and significant time-block $\times$ group interaction effect $\left(F_{(33,1144)}=4.38, p<0.001\right)$. Bonferroni corrected pairwise comparisons revealed no differences between adolescent control and cKO mice $(\boldsymbol{E})$. However, the levels of vertical activity of cKO mice were significantly higher than that of adolescent mice (both controls and cKOs) and adult littermate controls throughout all time points $(\boldsymbol{F})\left(^{*} p<0.05\right)$. $\boldsymbol{G}, \boldsymbol{H}$, Durations in center area of open field were not significantly different between control and $\mathrm{CKO}$ mice both at adolescent $(\boldsymbol{G})$ and adult ages $(\boldsymbol{H})$. 


\section{Adolescent (p30 40)}

A

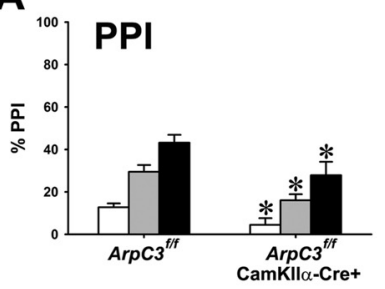

C

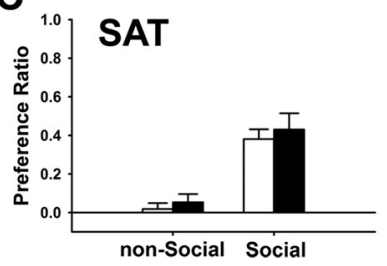

E

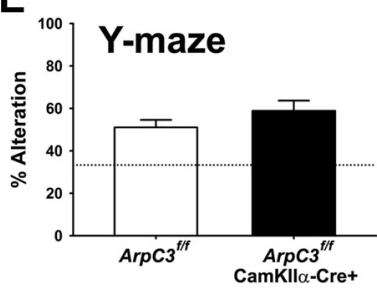

G

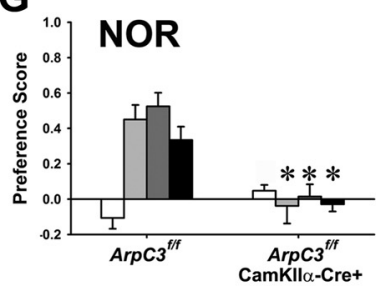

\section{Adult (p90 120)}

B

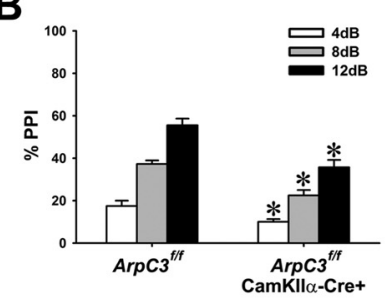

D

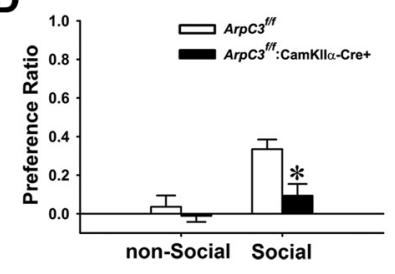

F

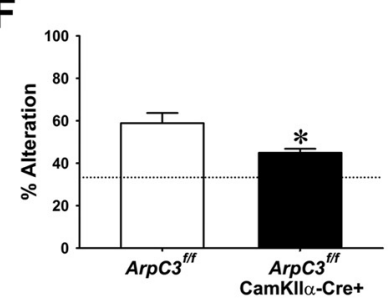

H

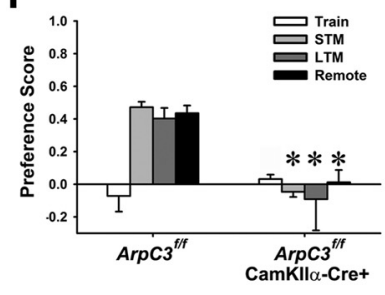

Figure 7. Analyses of PPI, sociability, working memory, and episodic memory in young and adult $A r p\left(3^{f / f}\right.$ :CaMKIl $\alpha$-Cre mice. $\boldsymbol{A}, \boldsymbol{B}$, Percentage PPI of acoustic startle responses at 4,8 , and $12 \mathrm{~dB}$ prepulses (over a $64 \mathrm{~dB}$ white noise background) (adolescent $n=15$ control, $n=10 \mathrm{cKO}$; adult $n=9$ control, $n=9(\mathrm{CK})$ ). ANOVA with repeated measure revealed significant main effects of test-phase $(4-12 \mathrm{~dB})\left(F_{(2,42)}=34.17, p<0.001\right.$ for adolescent mice; $F_{(2,32)}=$ $81.33, p<0.001$ for adults $)$ and genotype $\left(F_{(1,21)}=11.95, p<0.01\right.$ for adolescent mice; $F_{(1,16)}=31.67, p<0.001$ for adults), but no test-phase $\times$ genotype interactions. Bonferronicorrected pairwise comparisons noted that the PPI of mutants against all three prepulse levels $(4,8$, and $12 \mathrm{~dB})$ were decreased in both adolescent and adult mice compared with their littermate controls ( $\left.{ }^{*} p<0.05\right)$. C, $\boldsymbol{D}$, Preference ratio for nonsocial or social stimuli in the social affiliation test (SAT) (adolescent $n=13$ control, $n=13 \mathrm{cKO}$; adult $n=13$ control, $n=12 \mathrm{cKO}$ ). C, For adolescent mice, ANOVA with repeated measure revealed a significant main effects of test-phase $\left(F_{(1,23)}=48.71, p<0.001\right)$. However, there was no genotype effect $\left(F_{(1,23)}=\right.$ $0.632, p=0.43)$, nor test-phase $\times$ genotype interaction. $D$, For adult mice, ANOVA with repeated measure noted significant main effects of test-phase $\left(F_{(1,20)}=6.54, p<0.05\right)$ and genotype effect $\left(F_{(1,20)}=14.38, p<0.001\right)$, whereas no significant test-phase $\times$ genotype interaction was detected. Bonferroni comparisons showed that the social interactions of adult mutants with the stimulus mouse was decreased compared with littermate controls $\left({ }^{*} p<0.001\right) . \boldsymbol{E}, \boldsymbol{F}, \mathrm{Y}$-maze test of working memory showing the average of percentage correct alternations. Dotted line indicates percentage alternations expected by chance (33\%) (adolescent $n=14$ control, $n=13$ cK0; adult $n=9$ control, $n=9$ (KO). Independent $t$ test revealed that the correct alteration rate of adolescent mutant mice was not different from littermate controls $(\boldsymbol{E})\left(t_{(1,25)}=1.39, p=0.177\right)$, whereas adult mutants showed a significantly decreased correct alteration rate compared with their controls $(\boldsymbol{F})\left(t_{(1,16)}=2.52, p<0.05\right) . \mathbf{G}, \boldsymbol{H}$, Novel object recognition (NOR) test of short-term (STM), long-term (LTM), and remote memory. The preference score for the novel object is shown (adolescent $n=14$ control, $n=13 \mathrm{cKO}$; adult $n=9$ control, $n=9 \mathrm{CKO})$. ANOVA with repeated measure revealed significant main

PPI, a sensorimotor gating task, was analyzed next; this assay is particularly intriguing, since reduced PPI is considered an endophenotype for positive symptoms of schizophrenia in human patients that may appear before other symptoms (Cadenhead et al., 1993; Arguello and Gogos, 2006; Ziermans et al., 2011; Ziermans et al., 2012). Both adolescent and adult $\operatorname{Arp} C 3^{\text {fff: }}$ : CamKll $\alpha$-Cre mice showed significantly reduced PPI compared with their littermate controls (Fig. 7A,B); basal startle responses were similar between genotypes at both ages (data now shown). These data suggest that precognitive processes are affected earlier than activity in the ArpC $3^{f f}$ :CamKllo-Cre mice.

Based on our initial observations, we suspected that social interactions may be abnormal in the ArpC $3^{f / f}:$ CamKll $\alpha$-Cre mice, leading us to conduct a social affiliation test (Fig. $7 C, D$ ). Adolescent mutant and control mice strongly preferred the stimulus mouse compared with a nonsocial object (Fig. 7C). In contrast, adult mutants exhibited less preference for the social stimulus mouse than their controls (Fig. 7D), although the total number of contacts with social and nonsocial stimuli was not different between groups (data not shown), demonstrating that sociability declines significantly in the ArpC $3^{f / f}:$ CamKll $\alpha$-Cre mice as they reach adulthood.

Because the loss of ArpC3 reduced activity-dependent structural plasticity, we also analyzed cognitive behavior in the mutant mice. Cognitive symptoms of $A r p C 3^{f / f}:$ CamKll $\alpha$-Cre mice were assessed using Y-maze (working memory) and novel object recognition tests (episodic memory). Adolescent control and mutant mice engaged in similar numbers of alternations in the Y-maze, suggesting an intact working memory (Fig. 7E). In contrast, the percentage of alternations was slightly, but significantly decreased in the adult ArpC $3^{f / f}:$ CamKll $\alpha$-Cre mice, indicating their working memory was impaired (Fig. $7 F$ ). In the novel object recognition test (NOR), both adolescent and adult mutant mice showed a significant disruption of episodic learning and memory (Fig. 7G,H). Compared with controls, ArpC $3^{\text {fff }}:$ CamKll $\alpha$-Cre mice were severely impaired in their ability to distinguish between the familiar and novel object at $20 \mathrm{~min}, 24 \mathrm{~h}$, and 1 week following the training, demonstrating that $\operatorname{ArpC} 3^{f f f}:$ CamKll $\alpha$-Cre mice have early and pronounced deficits in short-term, longterm, and remote memory capabilities. Together, these data indicate that loss of ArpC3 in the ArpC $3^{\text {fff }}:$ CamKll $\alpha$-Cre mice results in an early and pervasive deficit in episodic memory, followed by impaired working memory in adulthood.

Overall, our study demonstrates that conditional deletion of ArpC3 in forebrain excitatory neurons leads to an early defect in structural synaptic plasticity, followed later by a loss of synapses onto dendritic spines. These synaptic abnormalities correspond with early impairment of PPI and episodic memory, later followed by hyperactivity, stereotypical behaviors, working memory deficits, and social isolation (Fig. 8).

\section{Discussion}

Genetic interactions between multiple rare allelic variants can predispose individuals to disorders such as ID, SZ, and ASD.

\section{$\leftarrow$}

effects of test-phase $\left(F_{(3,75)}=5.59, p<0.01\right.$ for adolescent mice; $F_{(3,42)}=3.53, p<0.05$ for adults), genotype $\left(F_{(1,25)}=64.91, p<0.001\right.$ for adolescent mice; $F_{(1,14)}=23.59, p<0.01$ for adults), and significant test-phase $\times$ genotype interaction effect $\left(F_{(3,75)}=19.15, p<0.001\right.$ for adolescent mice; $F_{(3,42)}=7.14, p<0.001$ for adults). Bonferroni-corrected pairwise comparisons noted that adolescent cKO mice have deficits in all three types of memory capability (short-, long-term, and remote memory) compared with those of littermate controls $\left({ }^{*} p<0.05\right)$. 


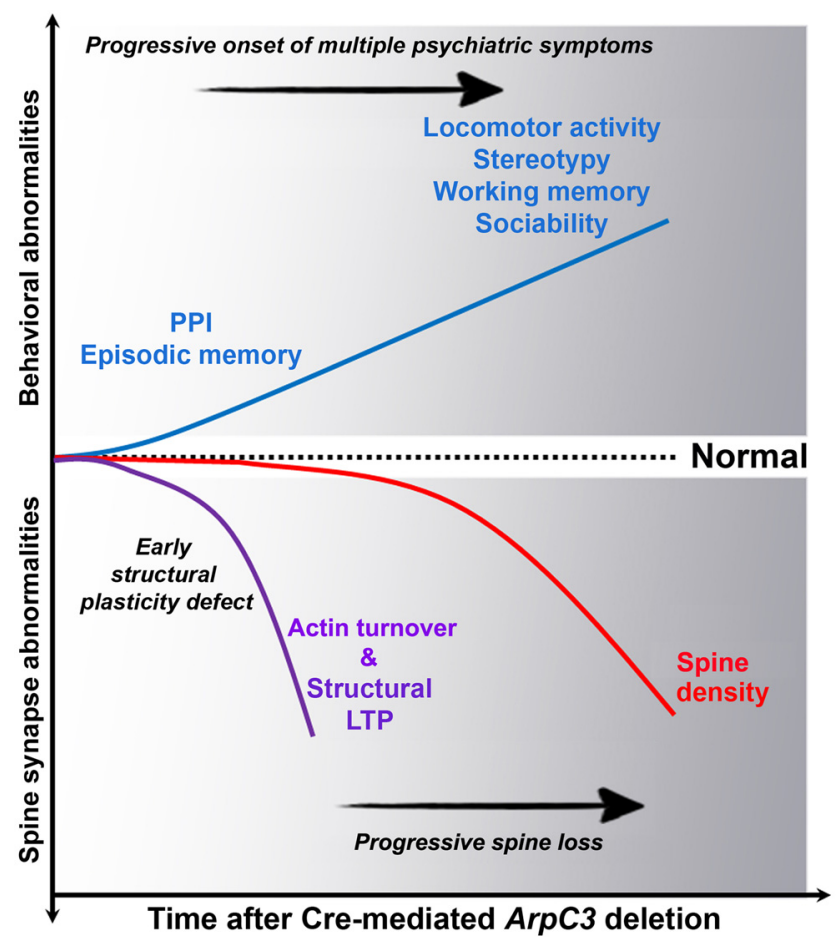

Figure 8. Schematic model summarizing the progressive development of synaptic and behavioral abnormalities following ArpC3 deletion. Loss of ArpC3 in postnatal excitatory neurons of forebrain results in two phases of progressive synaptic abnormalities; an early impairments of actin turnover and structural plasticity of spines (purple line), followed by a second phase of gradual loss of spine synapses (red line). Each phase is associated with a distinct progression of multiple behaviors related to psychiatric disorders (blue line). Dotted line indicates normal range.

Genomic studies of risk factors has led to a developing consensus that these disorders may reflect a signaling network or "pathway" dysfunction (Walsh et al., 2008; International Schizophrenia Consortium et al., 2009; Gilman et al., 2011; Sakai et al., 2011; Voineagu et al., 2011; Casey et al., 2012; Durand et al., 2012; Leblond et al., 2012; Sullivan, 2012); one candidate pathway is the regulation of the synaptic cytoskeleton. The Arp $2 / 3$ complex plays a central role in controlling actin polymerization, positioning it as a hub downstream of multiple genes implicated in psychiatric disorders (Kaufmann and Moser, 2000; Ramakers, 2002; Hayashi-Takagi et al., 2010; Ito et al., 2010; Durand et al., 2012).

Upon deletion of ArpC3 (a subunit of the Arp2/3 complex), the first phenotype to emerge was failure to maintain the equilibrium of structural plasticity associated with LTP and LTD. Subsequently, changes in spine morphology became evident, with the loss of large mushroom-shaped spines and an increase in filopodial-like spines. This asymmetry of spine structural plasticity may lead over time to an accumulation of unstable filopodial spines that could lead to reduced spine density in vivo (Grutzendler et al., 2002; Trachtenberg et al., 2002). Thus, Arp2/3 may be crucial for experience-dependent plasticity and long-term stabilization of spines in vivo. The loss of ArpC3 may also have other consequences, including an impairment in activity-dependent spinogenesis that also contributes to spine density in the postnatal period (Kwon and Sabatini, 2011). Importantly, abnormalities in spine morphology have been described in multiple genetic animal models of neuropsychiatric disorders, including SZ, ID, and ASD (Comery et al., 1997; Govek et al., 2004; Barros et al., 2009; Hayashi-Takagi et al., 2010; Ito et al., 2010; Carlson et al., 2011; Durand et al., 2012) and in postmortem analysis of patients with these disorders (Rudelli et al., 1985; Glantz and Lewis, 2000; Ramakers, 2002; Kolomeets et al., 2005; Hutsler and Zhang, 2010; Penzes et al., 2011), implying a close relationship between spine abnormalities and the pathology of neuropsychiatric disorders.

Corresponding to the time course of the evolving synaptic dysfunctions, $A r p C 3^{f / f}$ :CamKll $\alpha$-Cre mice progressively develop multiple behavioral abnormalities. The sequence of this progression suggests that PPI and episodic memory may be more sensitive to disturbances in plasticity, mimicking a prodromal state, while marked disruptions in motor responses and social behavior may be secondary to spine loss. Genes involved in actin signaling have been associated with multiple neuropsychiatric disorders; which of these might the CamKll $\alpha$-Cre driven loss of Arp2/3 best model? Overlap between signaling pathways and the synaptic and behavior phenotypes of SZ, ID, and ASD complicates the interpretation of genetic models of these disorders in experimental animals. No single behavioral abnormality observed in the ArpC3 cKO mice is specific for a single disorder, but the sum of the abnormalities best corresponds to other models of SZ-related disorders, since the mice progressively lose spine synapses and over time exhibit reduced PPI, cognitive deficits, hyperactivity, and social isolation.

SZ is distinguished from ID and ASD by several striking features. SZ symptoms have a delayed onset, typically appearing in adolescence or early adulthood (DeLisi, 1992; Insel, 2010). While the basis for this delay is unknown, accumulating evidence indicates that SZ evolves in distinct phases, with cognitive and some negative symptoms arising first, followed by the onset of psychosis (Tandon et al., 2009). Finally, the severity of symptoms may increase gradually over time. The basis for these changes may be related to structural alterations, as longitudinal studies report a progressive loss of gray matter in SZ brains (Bennett, 2011), corresponding with a gradual loss of dendritic spines (Glantz and Lewis, 2000).

Several lines of evidence support a role for dysregulation of pathways governing spine actin remodeling in SZ. DISC1, a susceptibility gene for SZ, has been shown to regulate Rac signaling to spine actin via the guanine nucleotide exchange factor Kalirin-7, whose deletion in mice results in a progressive loss of spines and several SZ-related behavioral abnormalities (Cahill et al., 2009). Postmortem analysis reveals decreased expression of proteins that regulate synaptic actin signaling, including Rhofamily GTPases (Hill et al., 2006). Another SZ-linked gene, DT$N B P 1$, encodes the protein disbindin-1, which assembles in a protein complex with Abil and WAVE family members implicated in the maintenance of normal spine morphology (Ito et al., 2010). Copy number variants associated with SZ also impact key cytoskeletal signaling molecules, including CYFIP1 and WRP/ srGAP3, which regulate Rac-to-WAVE signal transduction (Soderling et al., 2002; Stefansson et al., 2008; Addington and Rapoport, 2009; Zhao et al., 2012). Possible risk-associated loci for SZ also include genes encoding the Arp2/3 complex (Lips et al., 2011). Reductions in the levels of NMDA receptor subunits and PSD-95 similar to those we observe in the ArpC $3^{f / f}$ :CamKll $\alpha$ Cre mice have been reported also in individuals with SZ (Toro and Deakin, 2005; Kristiansen et al., 2006), consistent with the glutamate hypofunction theory of SZ (Javitt, 2004).

In summary, the cellular, biochemical, and behavioral results presented here support the possibility that abnormal signaling to the actin cytoskeleton via Arp2/3 is a common pathway that may underlie multiple classes of psychiatric symptoms. Intriguingly, the disruption of Arp2/3 in the forebrain can recapitulate the functional manifestations of many upstream candidate genes 
previously associated with SZ. Disruption of Arp $2 / 3$ in other circuits and neuronal cell types may be an effective approach to model disorders of the CNS thought to arise from altered actin signaling pathways.

\section{References}

Addington AM, Rapoport JL (2009) The genetics of childhood-onset schizophrenia: when madness strikes the prepubescent. Curr Psychiatry Rep 11:156-161. CrossRef Medline

Allen KM, Gleeson JG, Bagrodia S, Partington MW, MacMillan JC, Cerione RA, Mulley JC, Walsh CA (1998) PAK3 mutation in nonsyndromic X-linked mental retardation. Nat Genet 20:25-30. CrossRef Medline

Arguello PA, Gogos JA (2006) Modeling madness in mice: one piece at a time. Neuron 52:179-196. CrossRef Medline

Barros CS, Calabrese B, Chamero P, Roberts AJ, Korzus E, Lloyd K, Stowers L, Mayford M, Halpain S, Müller U (2009) Impaired maturation of dendritic spines without disorganization of cortical cell layers in mice lacking NRG1/ErbB signaling in the central nervous system. Proc Natl Acad Sci U S A 106:4507-4512. CrossRef Medline

Bennett MR (2011) Schizophrenia: susceptibility genes, dendritic-spine pathology and gray matter loss. Prog Neurobiol 95:275-300. CrossRef Medline

Blanpied TA, Kerr JM, Ehlers MD (2008) Structural plasticity with preserved topology in the postsynaptic protein network. Proc Natl Acad Sci U S A 105:12587-12592. CrossRef Medline

Bosch M, Hayashi Y (2012) Structural plasticity of dendritic spines. Curr Opin Neurobiol 22:383-388. CrossRef Medline

Bourne JN, Harris KM (2008) Balancing structure and function at hippocampal dendritic spines. Annu Rev Neurosci 31:47-67. CrossRef Medline

Cadenhead KS, Geyer MA, Braff DL (1993) Impaired startle prepulse inhibition and habituation in patients with schizotypal personality disorder. Am J Psychiatry 150:1862-1867. Medline

Cahill ME, Xie Z, Day M, Photowala H, Barbolina MV, Miller CA, Weiss C, Radulovic J, Sweatt JD, Disterhoft JF, Surmeier DJ, Penzes P (2009) Kalirin regulates cortical spine morphogenesis and disease-related behavioral phenotypes. Proc Natl Acad Sci U S A 106:13058-13063. CrossRef Medline

Carlson BR, Lloyd KE, Kruszewski A, Kim IH, Rodriguiz RM, Heindel C, Faytell M, Dudek SM, Wetsel WC, Soderling SH (2011) WRP/srGAP3 facilitates the initiation of spine development by an inverse F-BAR domain, and its loss impairs long-term memory. J Neurosci 31:2447-2460. CrossRef Medline

Casey JP, Magalhaes T, Conroy JM, Regan R, Shah N, Anney R, Shields DC, Abrahams BS, Almeida J, Bacchelli E, Bailey AJ, Baird G, Battaglia A, Berney T, Bolshakova N, Bolton PF, Bourgeron T, Brennan S, Cali P, Correia C, et al. (2012) A novel approach of homozygous haplotype sharing identifies candidate genes in autism spectrum disorder. Hum Genet 131:565-579. CrossRef Medline

Comery TA, Harris JB, Willems PJ, Oostra BA, Irwin SA, Weiler IJ, Greenough WT (1997) Abnormal dendritic spines in fragile X knockout mice: maturation and pruning deficits. Proc Natl Acad Sci U S A 94:54015404. CrossRef Medline

DeLisi LE (1992) The significance of age of onset for schizophrenia. Schizophr Bull 18:209-215. CrossRef Medline

Deng JV, Rodriguiz RM, Hutchinson AN, Kim IH, Wetsel WC, West AE (2010) MeCP2 in the nucleus accumbens contributes to neural and behavioral responses to psychostimulants. Nat Neurosci 13:1128-1136. CrossRef Medline

Durand CM, Perroy J, Loll F, Perrais D, Fagni L, Bourgeron T, Montcouquiol M, Sans N (2012) SHANK3 mutations identified in autism lead to modification of dendritic spine morphology via an actin-dependent mechanism. Mol Psychiatry 17:71-84. CrossRef Medline

Endris V, Wogatzky B, Leimer U, Bartsch D, Zatyka M, Latif F, Maher ER, Tariverdian G, Kirsch S, Karch D, Rappold GA (2002) The novel RhoGTPase activating gene MEGAP/ srGAP3 has a putative role in severe mental retardation. Proc Natl Acad Sci U S A 99:11754-11759. CrossRef Medline

Feinberg I (1982) Schizophrenia: caused by a fault in programmed synaptic elimination during adolescence? J Psychiatr Res 17:319-334. CrossRef Medline

Fortin DA, Davare MA, Srivastava T, Brady JD, Nygaard S, Derkach VA,
Soderling TR (2010) Long-term potentiation-dependent spine enlargement requires synaptic $\mathrm{Ca}^{2+}$-permeable AMPA receptors recruited by CaM-kinase I. J Neurosci 30:11565-11575. CrossRef Medline

Frangiskakis JM, Ewart AK, Morris CA, Mervis CB, Bertrand J, Robinson BF, Klein BP, Ensing GJ, Everett LA, Green ED, Pröschel C, Gutowski NJ, Noble M, Atkinson DL, Odelberg SJ, Keating MT (1996) LIM-kinasel hemizygosity implicated in impaired visuospatial constructive cognition. Cell 86:59-69. CrossRef Medline

Fukazawa Y, Saitoh Y, Ozawa F, Ohta Y, Mizuno K, Inokuchi K (2003) Hippocampal LTP is accompanied by enhanced F-actin content within the dendritic spine that is essential for late LTP maintenance in vivo. Neuron 38:447-460. CrossRef Medline

Gilman SR, Iossifov I, Levy D, Ronemus M, Wigler M, Vitkup D (2011) Rare de novo variants associated with autism implicate a large functional network of genes involved in formation and function of synapses. Neuron 70:898-907. CrossRef Medline

Glantz LA, Lewis DA (2000) Decreased dendritic spine density on prefrontal cortical pyramidal neurons in schizophrenia. Arch Gen Psychiatry 57:65-73. CrossRef Medline

Govek EE, Newey SE, Akerman CJ, Cross JR, Van der Veken L, Van Aelst L (2004) The X-linked mental retardation protein oligophrenin-1 is required for dendritic spine morphogenesis. Nat Neurosci 7:364-372. CrossRef Medline

Grutzendler J, Kasthuri N, Gan WB (2002) Long-term dendritic spine stability in the adult cortex. Nature 420:812-816. CrossRef Medline

Hayashi-Takagi A, Takaki M, Graziane N, Seshadri S, Murdoch H, Dunlop AJ, Makino Y, Seshadri AJ, Ishizuka K, Srivastava DP, Xie Z, Baraban JM, Houslay MD, Tomoda T, Brandon NJ, Kamiya A, Yan Z, Penzes P, Sawa A (2010) Disrupted-in-Schizophrenia 1 (DISC1) regulates spines of the glutamate synapse via Rac1. Nat Neurosci 13:327-332. CrossRef Medline

Hering H, Sheng M (2003) Activity-dependent redistribution and essential role of cortactin in dendritic spine morphogenesis. J Neurosci 23:11759_ 11769. Medline

Hill JJ, Hashimoto T, Lewis DA (2006) Molecular mechanisms contributing to dendritic spine alterations in the prefrontal cortex of subjects with schizophrenia. Mol Psychiatry 11:557-566. CrossRef Medline

Hutsler JJ, Zhang H (2010) Increased dendritic spine densities on cortical projection neurons in autism spectrum disorders. Brain Res 1309:83-94. CrossRef Medline

Insel TR (2010) Rethinking schizophrenia. Nature 468:187-193. CrossRef Medline

International Schizophrenia Consortium, Purcell SM, Wray NR, Stone JL, Visscher PM, O’Donovan MC, Sullivan PF, Sklar P (2009) Common polygenic variation contributes to risk of schizophrenia and bipolar disorder. Nature 460:748-752. Medline

Ito H, Morishita R, Shinoda T, Iwamoto I, Sudo K, Okamoto K, Nagata K (2010) Dysbindin-1, WAVE2 and Abi-1 form a complex that regulates dendritic spine formation. Mol Psychiatry 15:976-986. CrossRef Medline

Javitt DC (2004) Glutamate as a therapeutic target in psychiatric disorders. Mol Psychiatry 9:984-987. Medline

Kaufmann WE, Moser HW (2000) Dendritic anomalies in disorders associated with mental retardation. Cereb Cortex 10:981-991. CrossRef Medline

Kim CH, Lisman JE (1999) A role of actin filament in synaptic transmission and long-term potentiation. J Neurosci 19:4314-4324. Medline

Kim IH, Park SK, Hong ST, Jo YS, Kim EJ, Park EH, Han SB, Shin HS, Sun W, Kim HT, Soderling SH, Kim H (2009) Inositol 1,4,5-trisphosphate 3-kinase a functions as a scaffold for synaptic Rac signaling. J Neurosci 29:14039-14049. CrossRef Medline

Kolomeets NS, Orlovskaya DD, Rachmanova VI, Uranova NA (2005) Ultrastructural alterations in hippocampal mossy fiber synapses in schizophrenia: a postmortem morphometric study. Synapse 57:47-55. CrossRef Medline

Korobova F, Svitkina T (2010) Molecular architecture of synaptic actin cytoskeleton in hippocampal neurons reveals a mechanism of dendritic spine morphogenesis. Mol Biol Cell 21:165-176. CrossRef Medline

Kristiansen LV, Beneyto M, Haroutunian V, Meador-Woodruff JH (2006) Changes in NMDA receptor subunits and interacting PSD proteins in dorsolateral prefrontal and anterior cingulate cortex indicate abnormal regional expression in schizophrenia. Mol Psychiatry 11:737-747, 705. Medline

Kwon HB, Sabatini BL (2011) Glutamate induces de novo growth of func- 
tional spines in developing cortex. Nature 474:100-104. CrossRef Medline

Leblond CS, Heinrich J, Delorme R, Proepper C, Betancur C, Huguet G, Konyukh M, Chaste P, Ey E, Rastam M, Anckarsäter H, Nygren G, Gillberg IC, Melke J, Toro R, Regnault B, Fauchereau F, Mercati O, Lemière N, Skuse D, et al. (2012) Genetic and functional analyses of SHANK2 mutations suggest a multiple hit model of autism spectrum disorders. PLoS Genet 8:e1002521. CrossRef Medline

Lee HK, Kameyama K, Huganir RL, Bear MF (1998) NMDA induces longterm synaptic depression and dephosphorylation of the GluR1 subunit of AMPA receptors in hippocampus. Neuron 21:1151-1162. CrossRef Medline

Lips ES, Cornelisse LN, Toonen RF, Min JL, Hultman CM, Holmans PA, O’Donovan MC, Purcell SM, Smit AB, Verhage M, Sullivan PF, Visscher PM, Posthuma D (2011) Functional gene group analysis identifies synaptic gene groups as risk factor for schizophrenia. Mol Psychiatry. 17: 996-1007. CrossRef Medline

Mullins RD, Stafford WF, Pollard TD (1997) Structure, subunit topology, and actin-binding activity of the Arp2/3 complex from Acanthamoeba. J Cell Biol 136:331-343. CrossRef Medline

Murakoshi H, Wang H, Yasuda R (2011) Local, persistent activation of Rho GTPases during plasticity of single dendritic spines. Nature 472:100-104. CrossRef Medline

Okamoto K, Nagai T, Miyawaki A, Hayashi Y (2004) Rapid and persistent modulation of actin dynamics regulates postsynaptic reorganization underlying bidirectional plasticity. Nat Neurosci 7:1104-1112. CrossRef Medline

Park E, Na M, Choi J, Kim S, Lee JR, Yoon J, Park D, Sheng M, Kim E (2003) The Shank family of postsynaptic density proteins interacts with and promotes synaptic accumulation of the beta PIX guanine nucleotide exchange factor for Rac1 and Cdc42. J Biol Chem 278:19220-19229. CrossRef Medline

Penzes P, Cahill ME, Jones KA, VanLeeuwen JE, Woolfrey KM (2011) Dendritic spine pathology in neuropsychiatric disorders. Nat Neurosci 14: 285-293. CrossRef Medline

Piton A, Gauthier J, Hamdan FF, Lafrenière RG, Yang Y, Henrion E, Laurent S, Noreau A, Thibodeau P, Karemera L, Spiegelman D, Kuku F, Duguay J, Destroismaisons L, Jolivet P, Côté M, Lachapelle K, Diallo O, Raymond A, Marineau C, et al. (2011) Systematic resequencing of X-chromosome synaptic genes in autism spectrum disorder and schizophrenia. Mol Psychiatry 16:867-880. CrossRef Medline

Rácz B, Weinberg RJ (2008) Organization of the Arp2/3 complex in hippocampal spines. J Neurosci 28:5654-5659. CrossRef Medline

Ramakers GJ (2002) Rho proteins, mental retardation and the cellular basis of cognition. Trends Neurosci 25:191-199. CrossRef Medline

Ramakers GJ, Wolfer D, Rosenberger G, Kuchenbecker K, Kreienkamp HJ, Prange-Kiel J, Rune G, Richter K, Langnaese K, Masneuf S, Bösl MR, Fischer KD, Krugers HJ, Lipp HP, van Galen E, Kutsche K (2012) Dysregulation of Rho GTPases in the alphaPix/Arhgef6 mouse model of $\mathrm{X}$-linked intellectual disability is paralleled by impaired structural and synaptic plasticity and cognitive deficits. Hum Mol Genet 21:268-286. CrossRef Medline

Rudelli RD, Brown WT, Wisniewski K, Jenkins EC, Laure-Kamionowska M, Connell F, Wisniewski HM (1985) Adult fragile X syndrome. Cliniconeuropathologic findings. Acta Neuropathol 67:289-295. CrossRef Medline

Sakai Y, Shaw CA, Dawson BC, Dugas DV, Al-Mohtaseb Z, Hill DE, Zoghbi HY (2011) Protein interactome reveals converging molecular pathways among autism disorders. Sci Transl Med 3:86ra49. CrossRef Medline

Soderling SH, Binns KL, Wayman GA, Davee SM, Ong SH, Pawson T, Scott JD (2002) The WRP component of the WAVE-1 complex attenuates Rac-mediated signalling. Nat Cell Biol 4:970-975. CrossRef Medline

Star EN, Kwiatkowski DJ, Murthy VN (2002) Rapid turnover of actin in dendritic spines and its regulation by activity. Nat Neurosci 5:239-246. CrossRef Medline
Stefansson H, Rujescu D, Cichon S, Pietiläinen OP, Ingason A, Steinberg S, Fossdal R, Sigurdsson E, Sigmundsson T, Buizer-Voskamp JE, Hansen T, Jakobsen KD, Muglia P, Francks C, Matthews PM, Gylfason A, Halldorsson BV, Gudbjartsson D, Thorgeirsson TE, Sigurdsson A, et al. (2008) Large recurrent microdeletions associated with schizophrenia. Nature 455:232-236. CrossRef Medline

Strack S, Colbran RJ (1998) Autophosphorylation-dependent targeting of calcium/ calmodulin-dependent protein kinase II by the NR2B subunit of the N-methyl- D-aspartate receptor. J Biol Chem 273:20689-20692. CrossRef Medline

Sullivan PF (2012) Puzzling over schizophrenia: schizophrenia as a pathway disease. Nat Med 18:210-211. CrossRef Medline

Tandon R, Nasrallah HA, Keshavan MS (2009) Schizophrenia, "just the facts” 4. Clinical features and conceptualization. Schizophr Res 110:1-23. CrossRef Medline

Toro C, Deakin JF (2005) NMDA receptor subunit NRI and postsynaptic protein PSD-95 in hippocampus and orbitofrontal cortex in schizophrenia and mood disorder. Schizophr Res 80:323-330. CrossRef Medline

Trachtenberg JT, Chen BE, Knott GW, Feng G, Sanes JR, Welker E, Svoboda $\mathrm{K}$ (2002) Long-term in vivo imaging of experience-dependent synaptic plasticity in adult cortex. Nature 420:788-794. CrossRef Medline

Tsien JZ, Chen DF, Gerber D, Tom C, Mercer EH, Anderson DJ, Mayford M, Kandel ER, Tonegawa S (1996) Subregion- and cell type-restricted gene knockout in mouse brain. Cell 87:1317-1326. CrossRef Medline

Voineagu I, Wang X, Johnston P, Lowe JK, Tian Y, Horvath S, Mill J, Cantor RM, Blencowe BJ, Geschwind DH (2011) Transcriptomic analysis of autistic brain reveals convergent molecular pathology. Nature 474:380 384. CrossRef Medline

Walsh T, McClellan JM, McCarthy SE, Addington AM, Pierce SB, Cooper GM, Nord AS, Kusenda M, Malhotra D, Bhandari A, Stray SM, Rippey CF, Roccanova P, Makarov V, Lakshmi B, Findling RL, Sikich L, Stromberg T, Merriman B, Gogtay N, et al. (2008) Rare structural variants disrupt multiple genes in neurodevelopmental pathways in schizophrenia. Science 320:539-543. CrossRef Medline

Wendholt D, Spilker C, Schmitt A, Dolnik A, Smalla KH, Proepper C, Bockmann J, Sobue K, Gundelfinger ED, Kreutz MR, Boeckers TM (2006) ProSAP-interacting protein 1 (ProSAPiP1), a novel protein of the postsynaptic density that links the spine-associated Rap-Gap (SPAR) to the scaffolding protein ProSAP2/Shank3. J Biol Chem 281:13805-13816. CrossRef Medline

Wilson NK, Lee Y, Long R, Hermetz K, Rudd MK, Miller R, Rapoport JL, Addington AM (2011) A novel microduplication in the neurodevelopmental gene SRGAP3 that segregates with psychotic illness in the family of a COS proband. Case Rep Genet 2011:585893. Medline

Yae K, Keng VW, Koike M, Yusa K, Kouno M, Uno Y, Kondoh G, Gotow T, Uchiyama Y, Horie K, Takeda J (2006) Sleeping beauty transposonbased phenotypic analysis of mice: lack of Arpc3 results in defective trophoblast outgrowth. Mol Cell Biol 26:6185-6196. CrossRef Medline

Zhao Q, Li T, Zhao X, Huang K, Wang T, Li Z, Ji J, Zeng Z, Zhang Z, Li K, Feng G, St Clair D, He L, Shi Y (2012) Rare CNVs and Tag SNPs at 15q11.2 are associated with schizophrenia in the Han Chinese population. Schizophr Bull, in press. Medline

Zhou Q, Xiao M, Nicoll RA (2001) Contribution of cytoskeleton to the internalization of AMPA receptors. Proc Natl Acad Sci U S A 98:12611266. CrossRef Medline

Zhou Q, Homma KJ, Poo MM (2004) Shrinkage of dendritic spines associated with long-term depression of hippocampal synapses. Neuron 44: 749-757. CrossRef Medline

Ziermans TB, Schothorst PF, Sprong M, Magnée MJ, van Engeland H, Kemner C (2012) Reduced prepulse inhibition as an early vulnerability marker of the psychosis prodrome in adolescence. Schizophr Res 134:10-15. CrossRef Medline

Ziermans T, Schothorst P, Magnée M, van Engeland H, Kemner C (2011) Reduced prepulse inhibition in adolescents at risk for psychosis: a 2-year follow-up study. J Psychiatry Neurosci 36:127-134. Medline 